\title{
TAKE A CLOSER LOOK AT TRIALS
}

\section{The Global Consortium Study of Neurological Dysfunction in COVID-19 (GCS-NeuroCOVID): Development of Case Report Forms for Global Use}

\author{
Molly McNett ${ }^{*}$, Ericka L. Fink ${ }^{2}$, Michelle Schober ${ }^{3}$, Shraddha Mainali ${ }^{4}$, Raimund Helbok ${ }^{5}$, \\ Courtney L. Robertson ${ }^{6}$, Jorge Mejia-Mantilla, Pedro Kurtz ${ }^{8}$, Cássia Righy ${ }^{9}$, Juan D. Roa ${ }^{10}$, \\ Carlos Villamizar-Rosales ${ }^{11}$, Valeria Altamirano ${ }^{11}$, Jennifer A. Frontera ${ }^{12}$, Nelson Maldonado ${ }^{13}$, David Menon ${ }^{14}$, \\ Jose Suarez ${ }^{15}$ and Sherry H. Y. Chou ${ }^{16}$
}

\begin{abstract}
Since its original report in January 2020, the coronavirus disease 2019 (COVID-19) due to Severe Acute Respiratory Syndrome coronavirus 2 (SARS-CoV-2) infection has rapidly become one of the deadliest global pandemics. Early reports indicate possible neurological manifestations associated with COVID-19, with symptoms ranging from mild to severe, highly variable prevalence rates, and uncertainty regarding causal or coincidental occurrence of symptoms. As neurological involvement of any systemic disease is frequently associated with adverse effects on morbidity and mortality, obtaining accurate and consistent global data on the extent to which COVID-19 may impact the nervous system is urgently needed. To address this need, investigators from the Neurocritical Care Society launched the Global Consortium Study of Neurological Dysfunction in COVID-19 (GCS-NeuroCOVID). The GCS-NeuroCOVID consortium rapidly implemented a Tier 1, pragmatic study to establish phenotypes and prevalence of neurological manifestations of COVID-19. A key component of this global collaboration is development and application of common data elements (CDEs) and definitions to facilitate rigorous and systematic data collection across resource settings. Integration of these elements is critical to reduce heterogeneity of data and allow for future high-quality meta-analyses. The GCSNeuroCOVID consortium specifically designed these elements to be feasible for clinician investigators during a global pandemic when healthcare systems are likely overwhelmed and resources for research may be limited. Elements include pediatric components and translated versions to facilitate collaboration and data capture in Latin America, one of the epicenters of this global outbreak. In this manuscript, we share the specific data elements, definitions, and rationale for the adult and pediatric CDEs for Tier 1 of the GCS-NeuroCOVID consortium, as well as the translated versions adapted for use in Latin America. Global efforts are underway to further harmonize CDEs with other large consortia studying neurological and general aspects of COVID-19 infections. Ultimately, the GCS-NeuroCOVID consortium network provides a critical infrastructure to systematically capture data in current and future unanticipated disasters and disease outbreaks.
\end{abstract}

Keywords: COVID-19, SARS-CoV2, Disease prevalence, Neurological manifestations, Neurological symptoms, Coronavirus, Common data element, Case report form

*Correspondence: mcnett.21@osu.edu

${ }^{1}$ College of Nursing, The Ohio State University, Columbus, OH, USA

Full list of author information is available at the end of the article

\section{勿 Springer}




\section{Introduction}

The coronavirus disease 2019 (COVID-19) pandemic continues to escalate worldwide, with over 18 million people infected and over 696,000 deaths as of August, 2020. While some geographic regions experience peak surges, followed by consistent decreases in the number of patients testing positive for Severe Acute Respiratory Syndrome coronavirus 2 (SARS-CoV-2), other regions remain inundated with high volumes of infections, hospitalizations, and deaths [1]. Scientific reports from various regions are prolific, published with the intent of rapidly sharing knowledge regarding prevalence, treatment, and outcomes of infected individuals. Numerous reports of neurological symptoms and manifestations seemingly associated with SARS-CoV-2 infection continue to emerge, with spectrum of neurological manifestations ranging from mild (anosmia, ageusia, and headache) to severe (coma, seizures, hypoxic brain injury encephalopathy, stroke, cerebral hemorrhage, posterior reversible encephalopathy, and Guillain-Barré syndrome) [2-17]. Similarly, prevalence estimates across these reports range from 3.5 to $84 \%[5-7,12,16]$, with many studies not controlling for confounding factors or differentiating between levels of care or severity of systemic infection. Given the continued escalation of the global COVID19 pandemic and the rapidity of emerging information from regional reports on neurological manifestations of COVID-19, it has become increasingly difficult to ascertain accurate estimates on prevalence and severity of neurological dysfunctions. As a result, critical data on causality versus recrudescence of preexisting neurological conditions versus coincident findings of COVID-19 are lacking. Furthermore, recent attempts at pooled analysis are proven unsuccessful due to substantial heterogeneity across populations, sites, and data components [6].

A global, systematic, and collaborative approach to knowledge development in this pandemic is critical [18]. Fragmented reports create ambiguity about case definitions, clinical findings, and empiric treatments, potentially leading to administration of ineffective or harmful regimens and public alarm due to inaccurate conclusions about causation in the absence of sound scientific methodology $[14,19]$. Data gathering in a global pandemic must include diversity in age, sex, race, ethnicity, geographic region, and resource settings. Researchers must utilize a collaborative and pragmatic approach feasible for members of the healthcare team, as many research teams do not have access to hospitalized patients during a pandemic crisis. To this end, we rapidly established the Global Consortium Study of Neurological Dysfunction in COVID-19 (GCS-NeuroCOVID) and launched a Tier 1 basic study to gather essential data on acute neurological manifestations of COVID-19 captured by frontline providers in the midst of this pandemic [20]. The objective of this study is to pragmatically and systematically determine the major phenotypes of neurological symptoms and estimate their global prevalence among hospitalized COVID-19 patients. All acute care hospitals caring for COVID-19 patients are eligible to register as sites through a central Web portal [21]. The consortium employs an accelerated process to develop consensus common data element (CDE) and definitions as previously described. Whenever possible, we utilized any consensus CDEs already developed through the National Institute of Health (NIH) CDE process [22, 23].

As COVID-19 infection is associated with age- and race-dependent disease prevalence, severity, symptoms, and outcomes, the GCS-NeuroCOVID consortium study uses CDEs specifically designed for adult and pediatric populations that include race and ethnicity designations. Additionally, the GCS-NeuroCOVID consortium collaborated closely with partners in Latin America to harmonize data elements and definitions, resulting in the development of Spanish and Portuguese versions of case report forms (CRFs).

\section{Methods}

The aims, design, and methodology of the GCS-NeuroCOVID research program are previously reported [20]. In brief, the study employs a nimble, tiered design to determine the prevalence, severity, predictors, and outcomes of neurological manifestations among hospitalized patients across the age span with COVID-19 infection. A key element is CRFs that are readily available in multiple languages and applicable across sites and settings. International guidelines for good clinical practices in research define CRFs as "...specialized documents designed to record all protocol-required information to be reported on each subject" [24]. As such, CRFs are a critical component to ensure internal validity of any study, particularly for multisite investigations.

\section{GCS-NeuroCOVID Consortium CRF: Adult}

Guiding principles underlying development of the CRF for the GCS-NeuroCOVID investigation center on feasibility and harmonization. Feasibility refers to the ability of frontline clinicians to record observations of neurological manifestations among hospitalized COVID-19 patients with minimal burden, care delivery disruption, and no additional risk of exposure to providers. Given the sustained surge of cases worldwide, lack of adequate personal protective equipment (PPE), and limited resources for clinical research particularly during a pandemic, it is paramount to consider practical aspects to ensure feasibility of study initiation and completion. The acquisition of these data elements must not involve 
increased SARS-CoV-2 exposure risk for frontline clinical providers or require additional PPE use for research purposes alone. Data elements must have clear, simple, and specific definitions to optimize collection of highquality data with minimal errors or missing values. Data definitions must be easy to use and not require specialized expertise in neurological examinations for accurate data acquisition. Data elements should be commonly available regardless of resource levels of the acute care hospital to encourage participation and broad inclusion of all regions and hospitals that care for acute COVID-19 patients. Data elements need to capture overall severity of illness, because severe single- or multi-organ failures can result in secondary neurological sequelae, regardless of the original etiology of organ failure.

Creation of these initial highly pragmatic data elements provides the foundation for the Tier 1 study of GCSNeuroCOVID. The aim of the Tier 1 study is to systematically record data to identify the major phenotypes and prevalence of neurological symptoms among hospitalized patients with COVID-19 infection. As such, it is designed to be a minimal dataset that captures the most high-value data elements that are feasible to obtain in the challenging clinical environment during a pandemic where many routine diagnostic data, such as imaging studies, may not be available due to infection containment considerations or an overwhelmed health system. To address this, we further divided this basic and minimal set of Tier 1 CDEs into Core and Supplemental CDEs (Table 1). Core elements represent the minimal dataset that can be rapidly and easily captured during initial patient triage and care. Core CDEs should be recorded as completely as possible. Supplemental elements capture additional clinical characteristics, basic pre-morbid conditions, laboratory values, and outcome measures beyond acute hospitalization.

An added benefit of pragmatic data elements is the possibility for an expedited institutional review board (IRB) process at single-center sites. During pandemic surges, many sites limit research operations to reduce risk of exposure or facilitate re-allocation of staff to needed areas. As such, there may be limited personnel to review and approve lengthy or complex research protocols, and mechanisms for contract negotiations for data sharing may be temporarily suspended. A pragmatic protocol deemed not greater than minimal risk may be feasibly approved at sites using a single-center approval process. Subsequent amendments when resources are not as limited may then be made to establish data-sharing agreements via a central data coordinating center to pool data from participating sites for analysis and ensure use of secure platforms for protected health information (PHI).

The second principle of global CRF development includes data harmonization. Alignment of data elements and definitions across sites and studies serves the vital role of reducing heterogeneity of findings across studies, thus allowing for data pooling, systematic reviews, metaanalyses, and development of evidence-based guidelines based on a body of high-quality evidence. These factors are of critical importance when developing CRFs for a global consortium during a pandemic. As data rapidly become available, it is crucial to be able to cumulatively synthesize findings across studies to draw accurate conclusions and drive care decisions in real time.

To this end, the GCS-NeuroCOVID adult CRF aligns data fields and definitions with CDEs from the NIH where applicable when documenting neurological manifestations observed in COVID-19 infection. Our investigator team also engaged with emerging and existing consortiums to align common definitions across COVID19 populations and to have CRFs available in other languages to encourage participation across geographic regions and resource settings.

\section{Development of Adult Spanish Version CRF}

The GCS-NeuroCOVID consortium includes many sites located in primary Spanish-speaking regions. The Regional South American chapter of the Neurocritical Care Society was instrumental in aligning collaborations to facilitate participation among member sites and regional groups. To minimize data collection burden for the frontline clinicians at those sites and promote data fidelity, we developed Spanish language versions of study documents and CRF (Table 2). Spanish translation was performed by trained research team member (VA) and neurologist $(\mathrm{CV})$ at the central coordinating center (University of Pittsburgh) and reviewed and edited by global partners in primary Spanish-speaking regions (JM, NM). Data elements were reviewed and adjusted for applicability to the local region. Specifically, we avoided using medical abbreviations as there are variabilities in regional customs.

The Latin American Brain Injury Consortium (LABIC) is the association of neurointensivists in Latin America. LABIC's missions are (1) to promote education in neurointensive care and (2) to foster neurocritical care research and thereby improve clinical care and patient outcome throughout Latin America. LABIC consists of over 400 critical care professionals from Patagonia to México and the Caribbean countries who are dedicated to improve care and outcome of their neurological patients. The LABIC consortium has a track record of successful multicenter collaboration and research such as the publication of consensus guidelines for traumatic brain injury management [25]. The LABIC consortium is actively developing research initiatives and collaborations with global partners such as the South American chapter of 


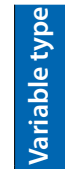

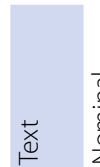

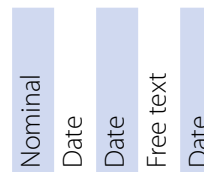

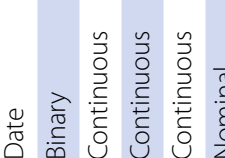
$\frac{\bar{c}}{\stackrel{\bar{c}}{\xi}}$

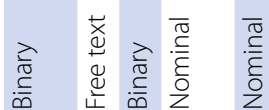
离 들

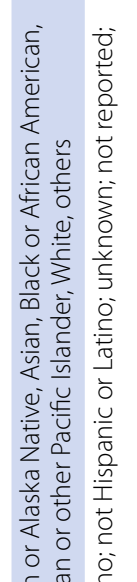

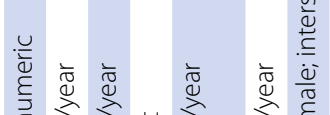

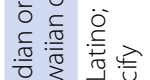
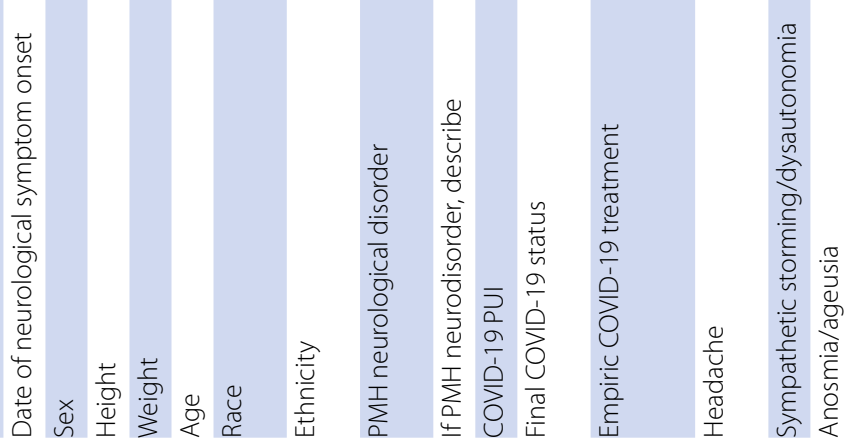


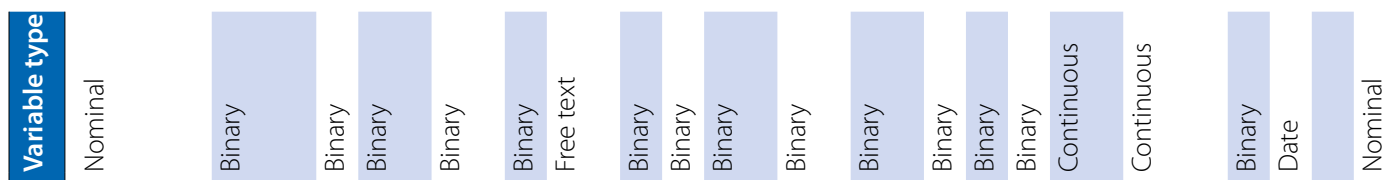

$\stackrel{\underline{0}}{\underline{\underline{v}} \underline{\underline{U}}}$

$\frac{\tilde{\varepsilon}}{\varepsilon} \frac{\mathrm{O}}{\mathrm{c}}$

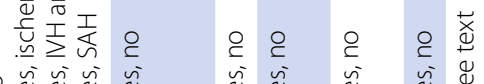

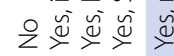

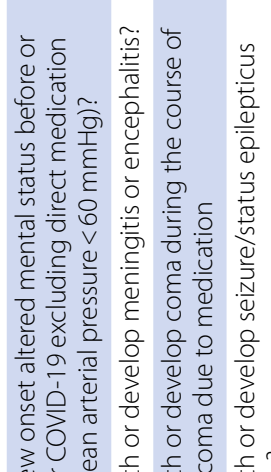

उU ज्ञ

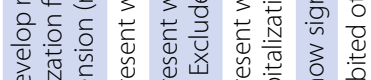

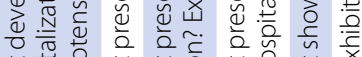

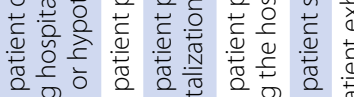

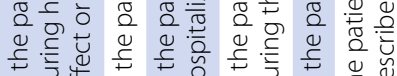

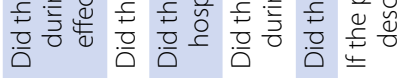

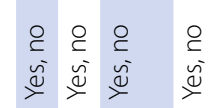

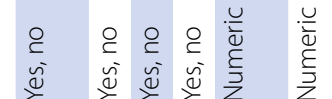

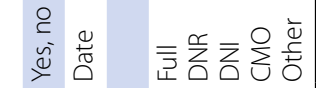
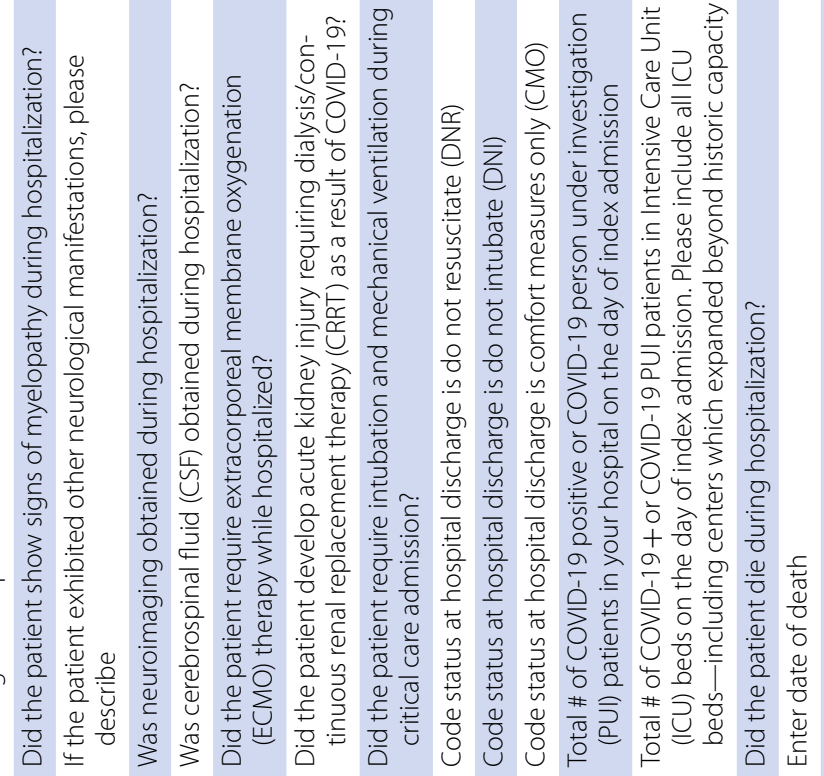

7
0
0
0
0
0
0
0
0
0
0
0
0
0
0
0
0
0
0
0
0
0
0
0
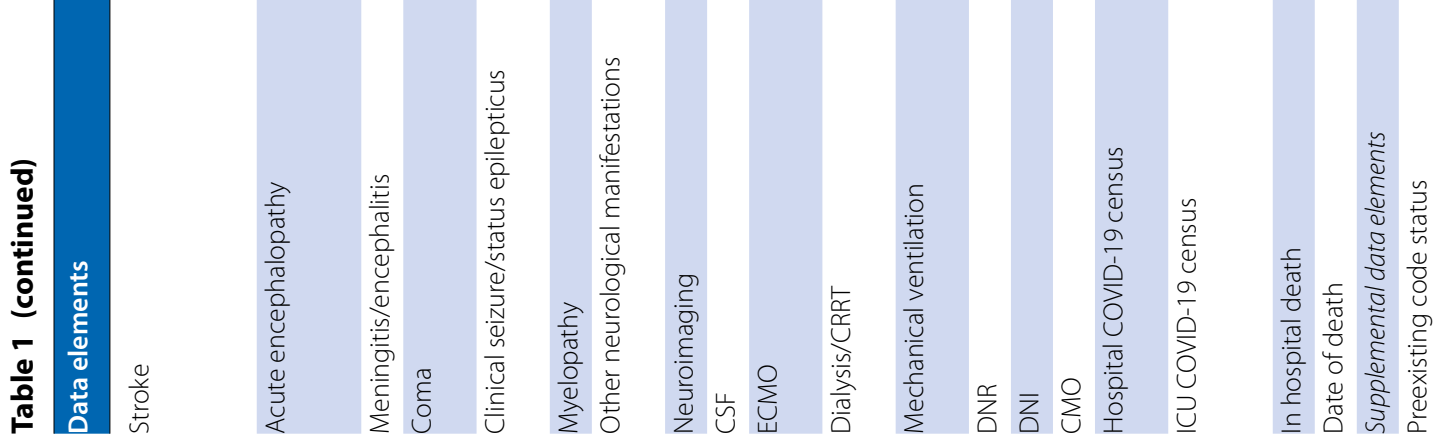


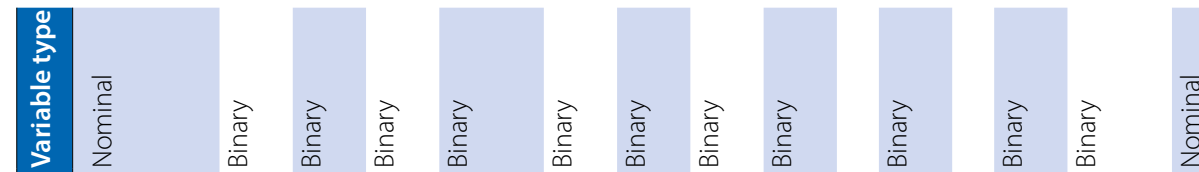
$\stackrel{\substack{0 \\ \frac{0}{0}}}{\stackrel{2}{c}}$ 4 \&

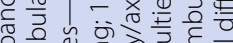

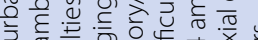

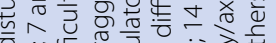
0 $m$ ह क है कू

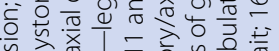
जे ठำ

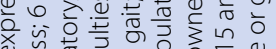
बथ

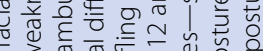
$3 \pi \frac{0}{\frac{0}{4}}$ бั क्षे

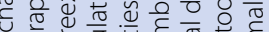
र क्ष थั

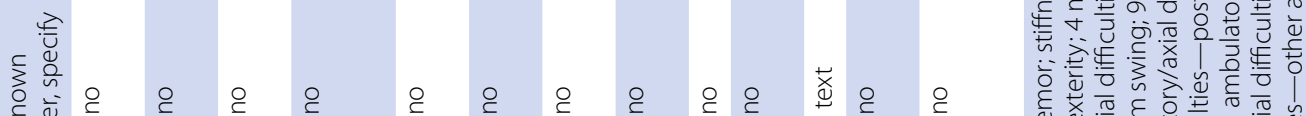

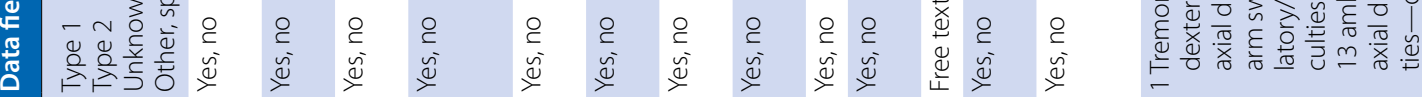

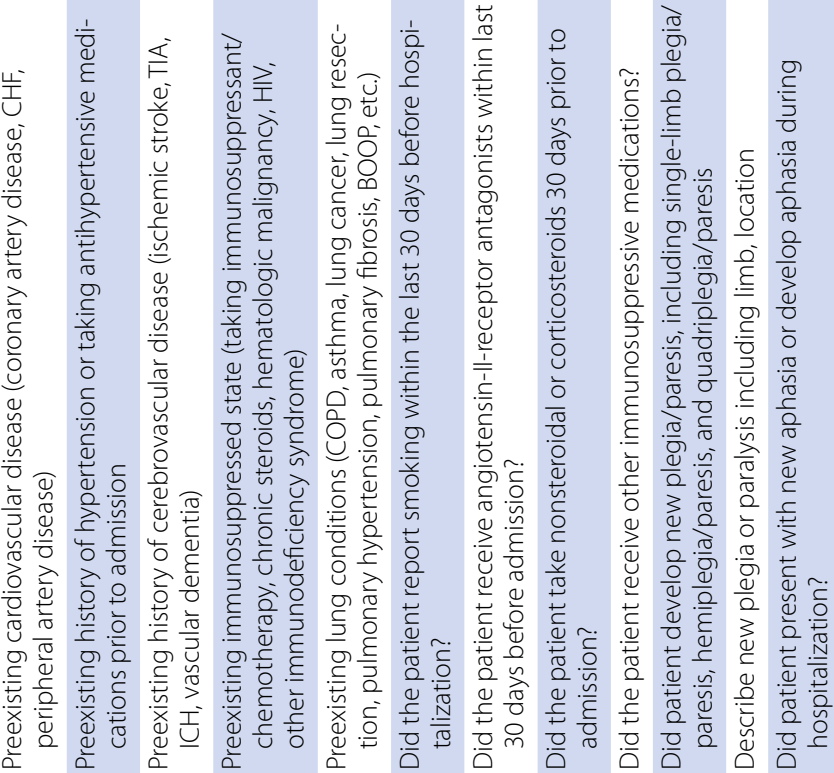
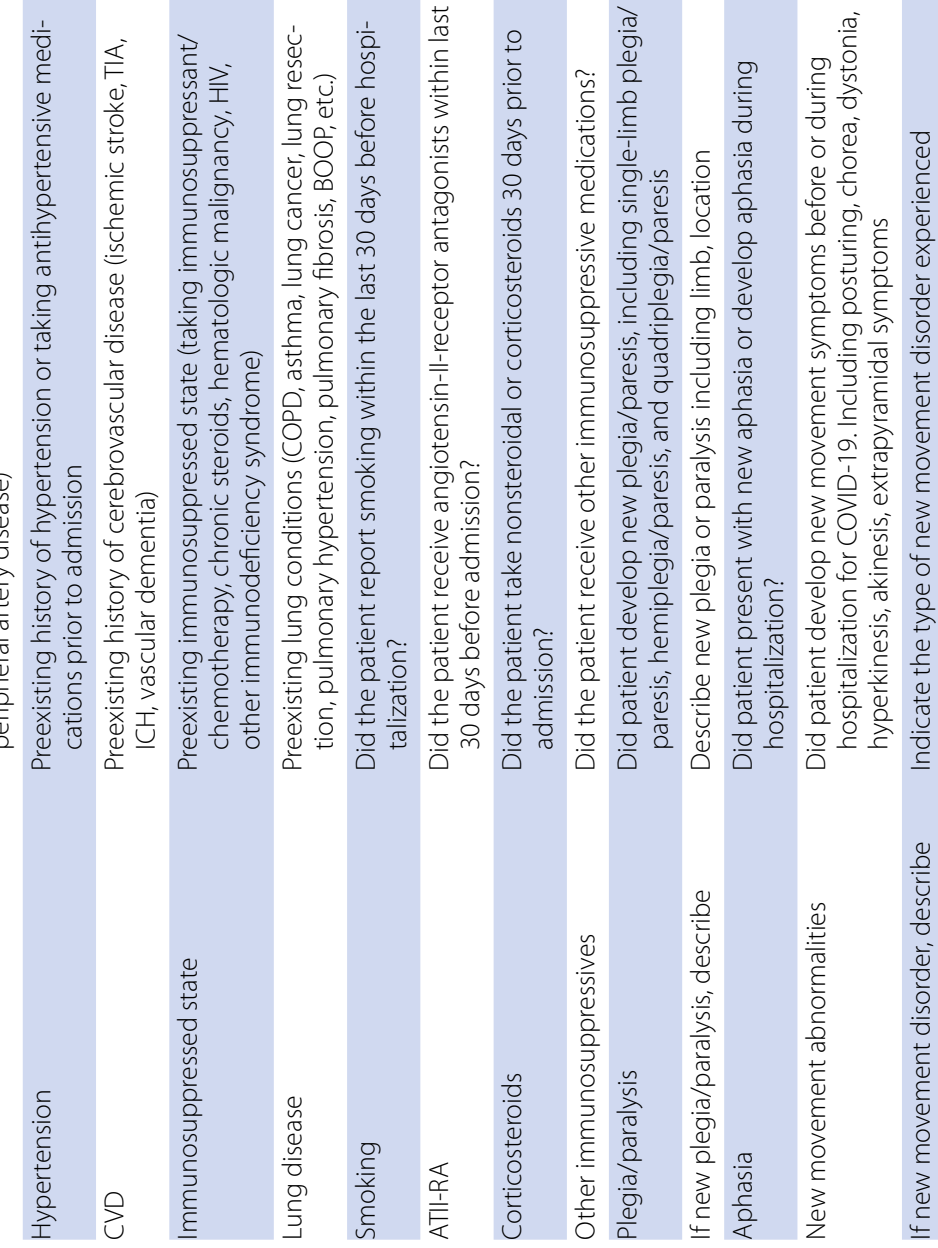

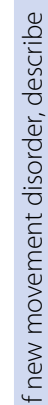
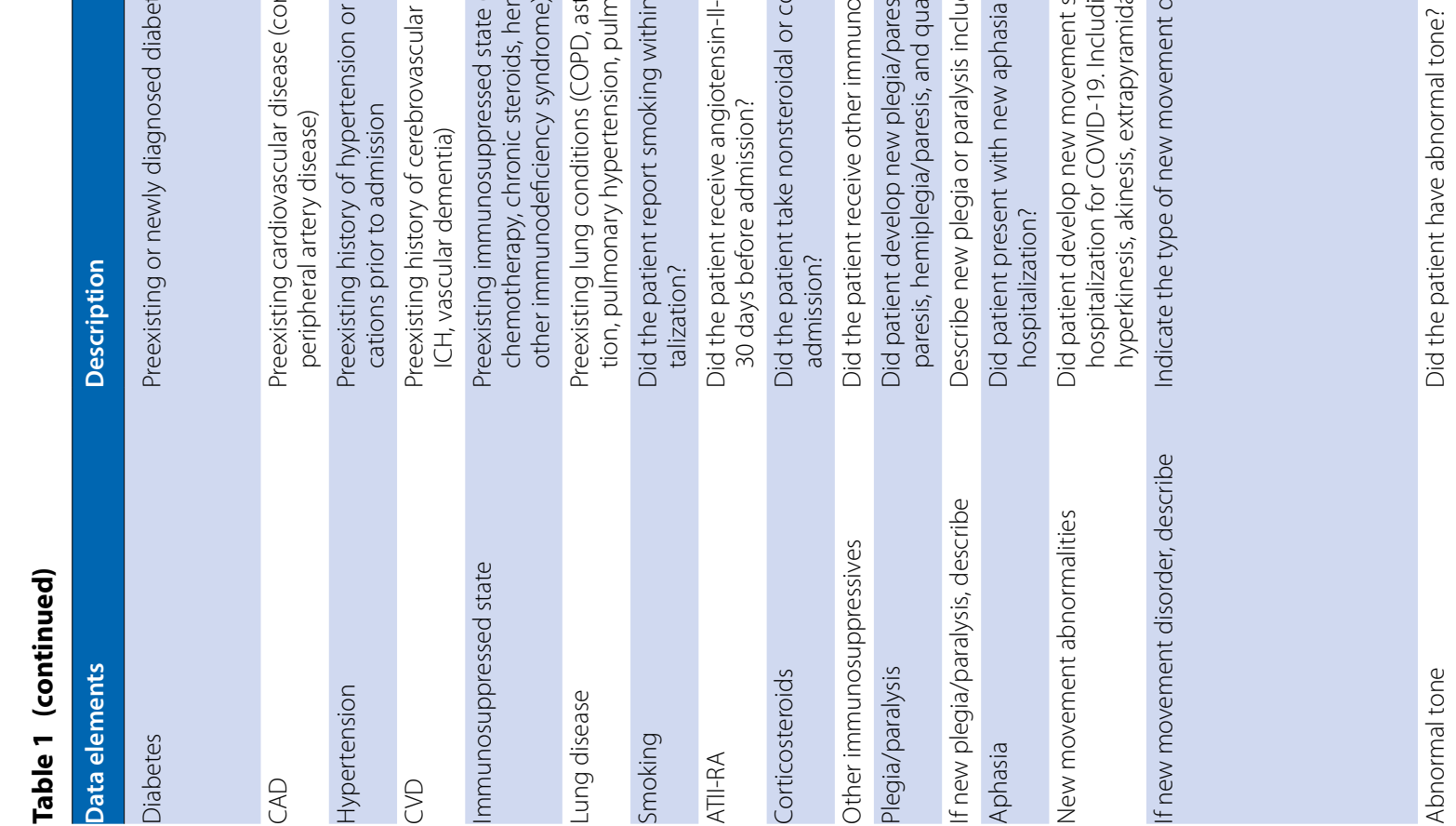


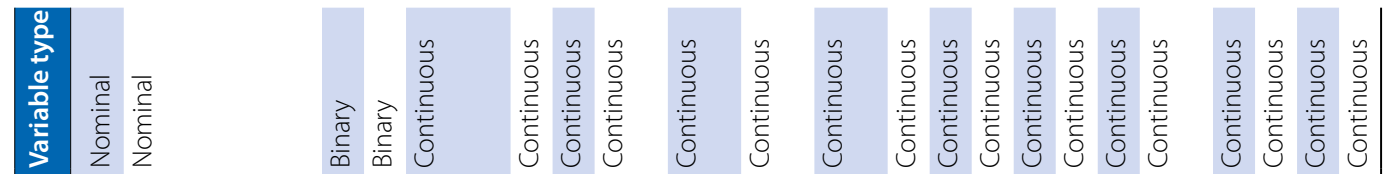

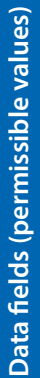

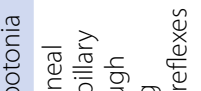

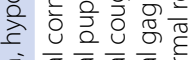

क्ष

获

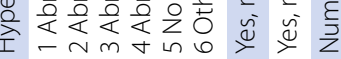

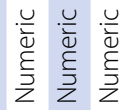

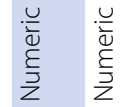

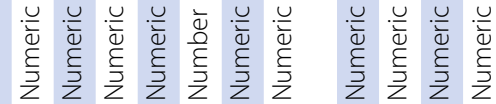
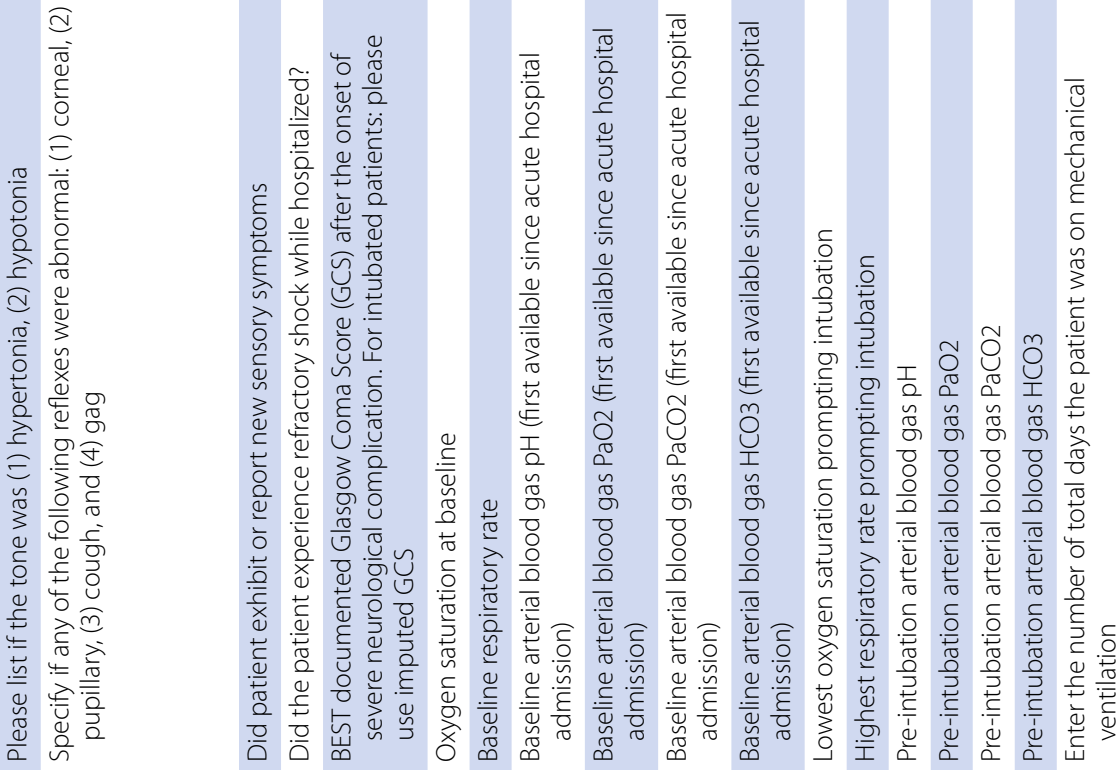

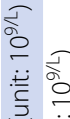

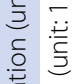

단)

ญे है एँ

ᄃ

节高焉

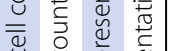

ত⿱艹

일

文 है

卷苛
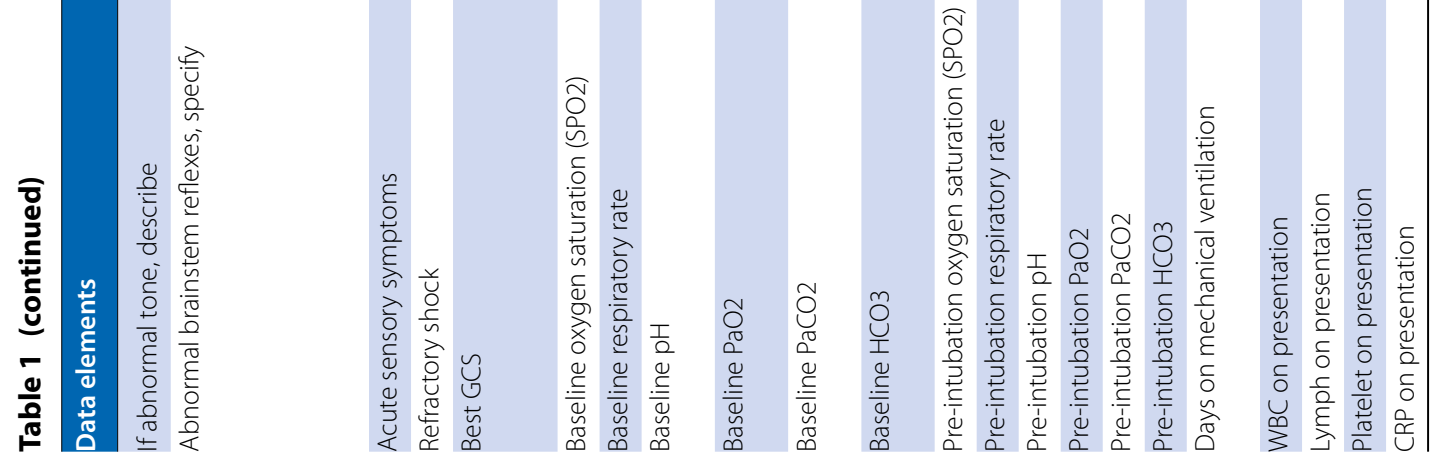


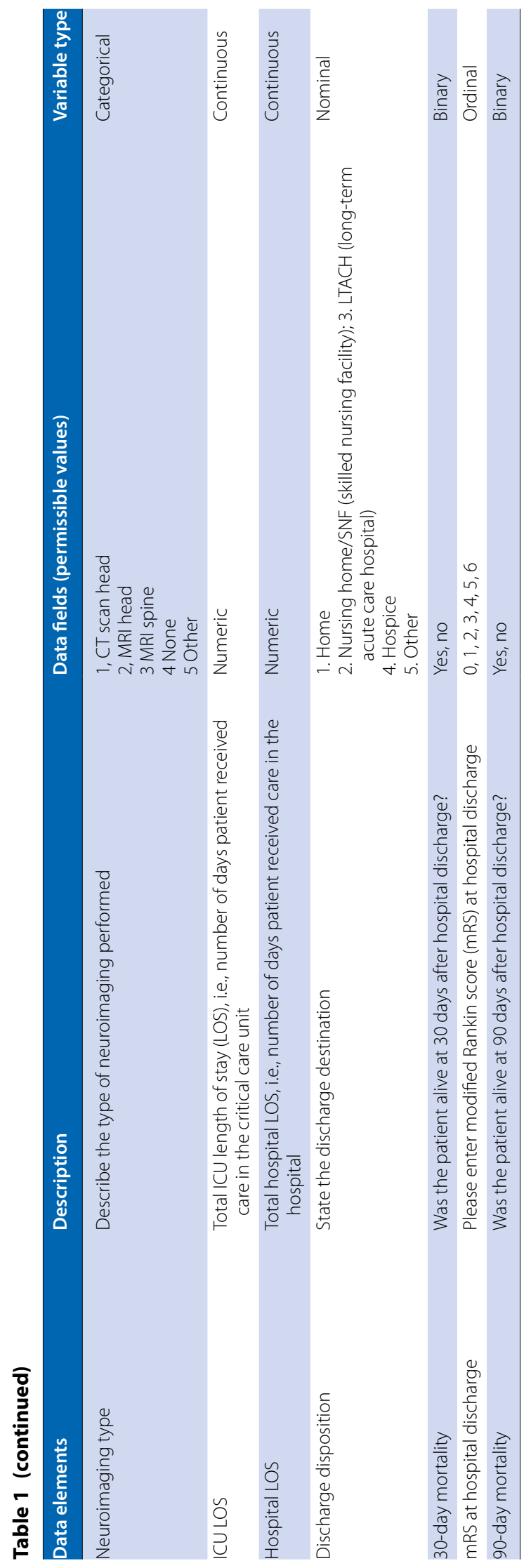




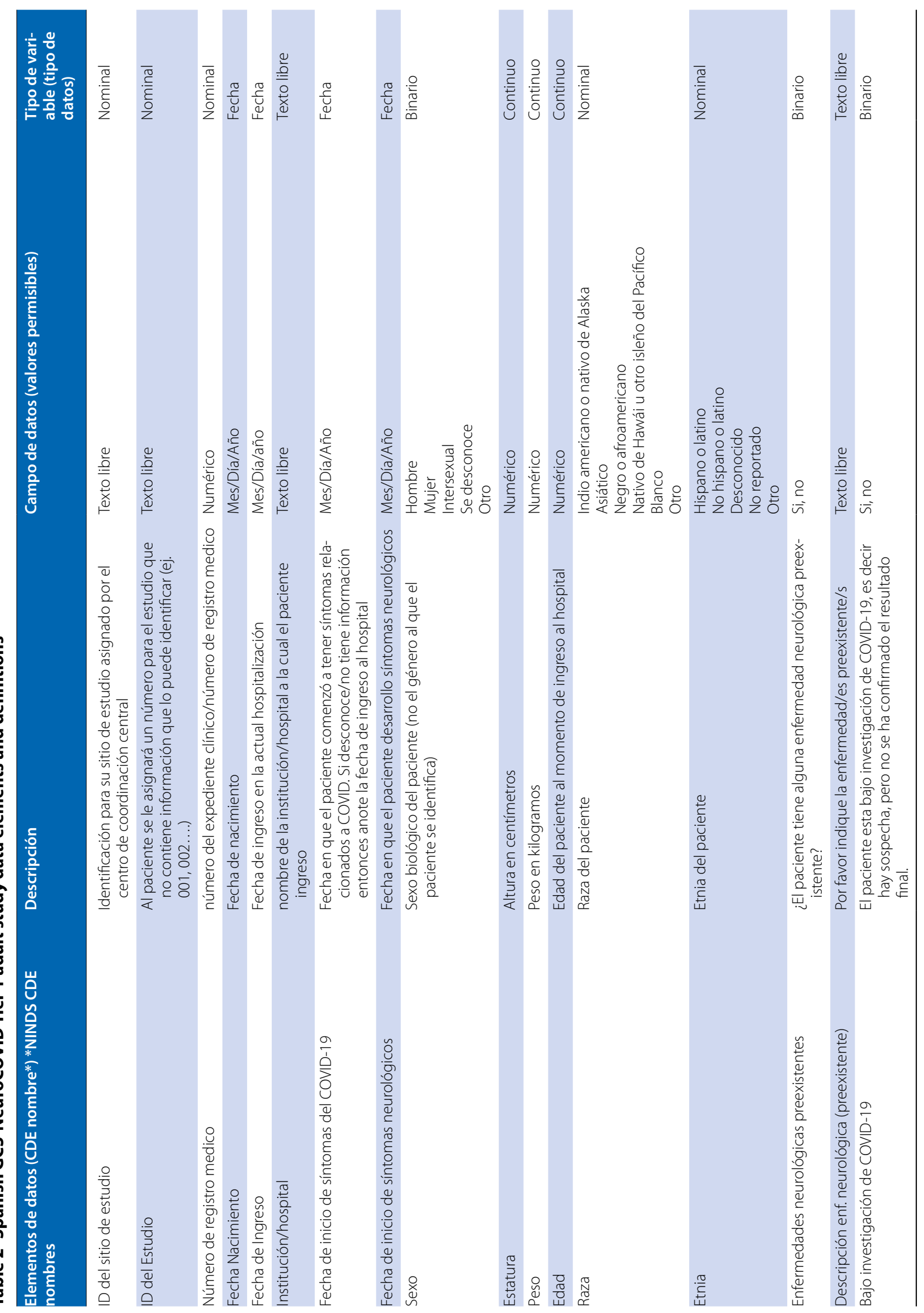




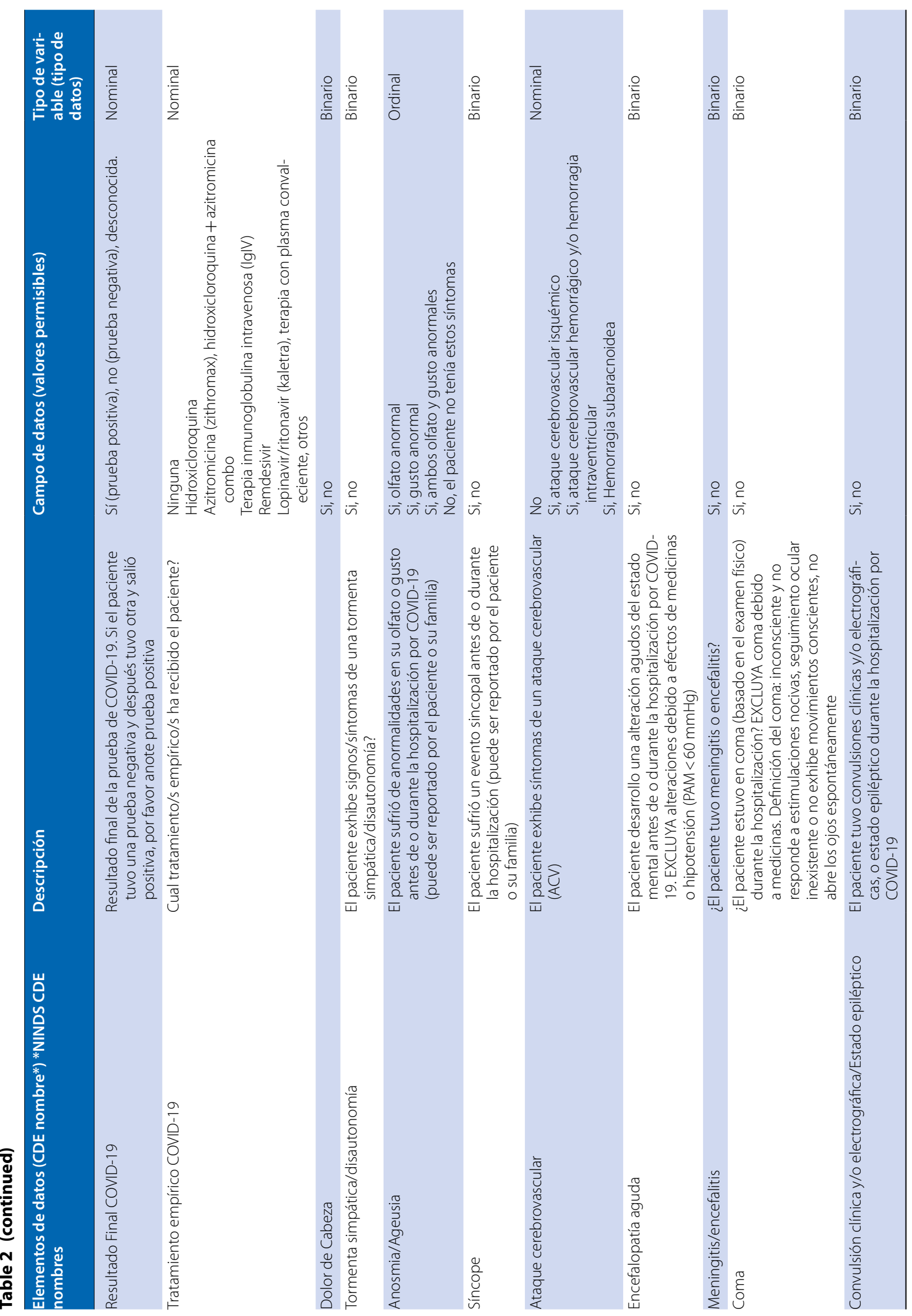




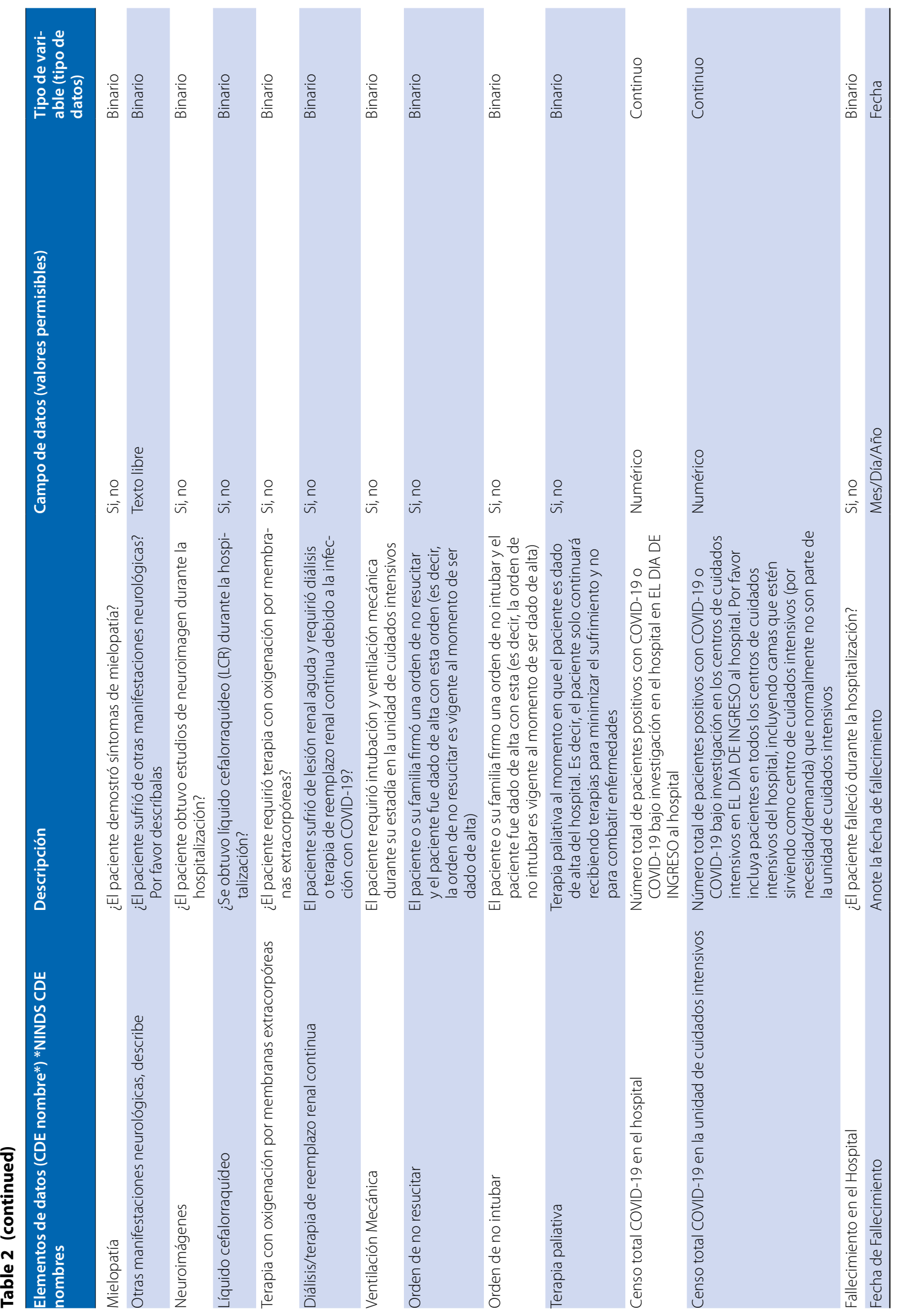




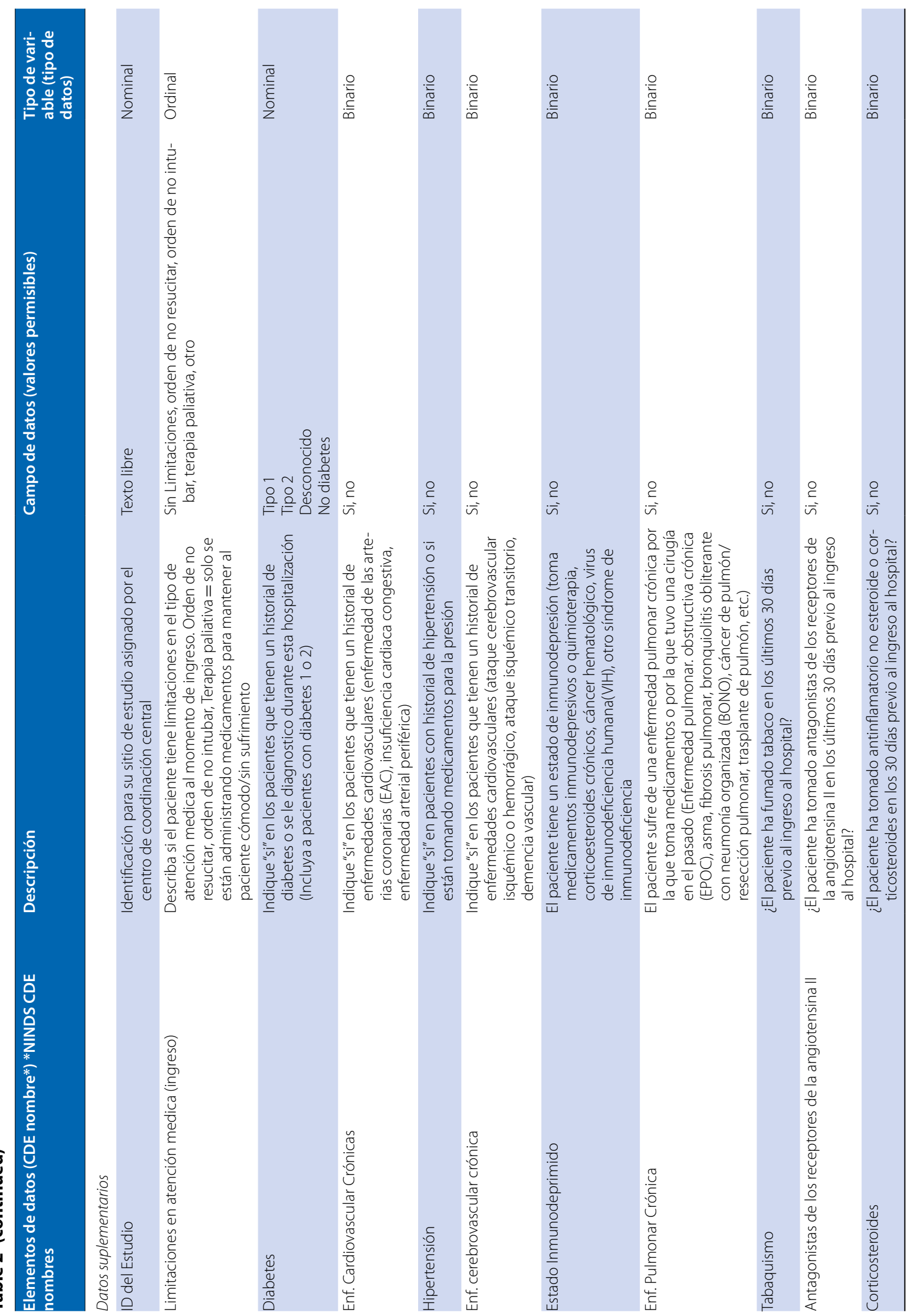




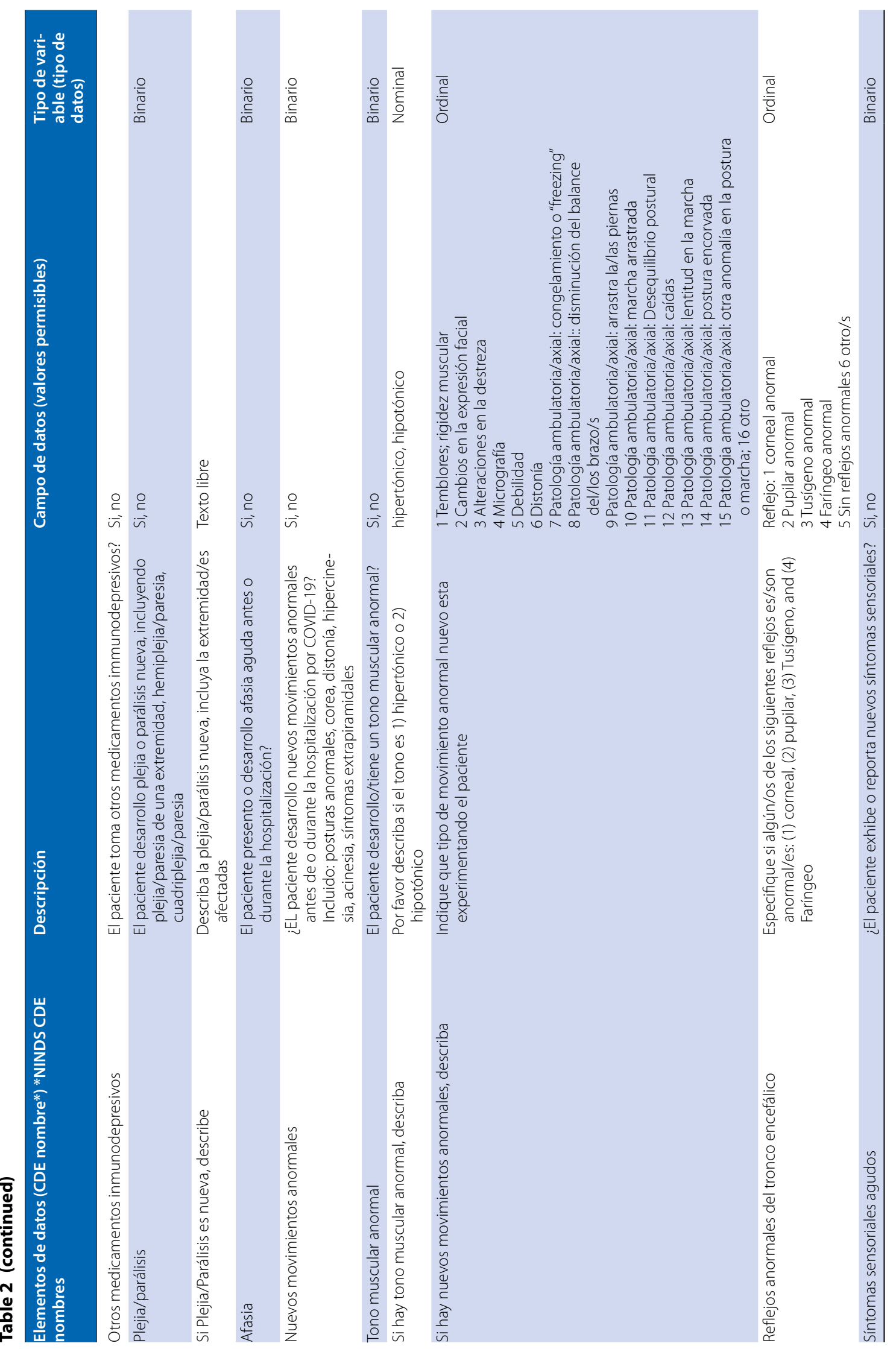




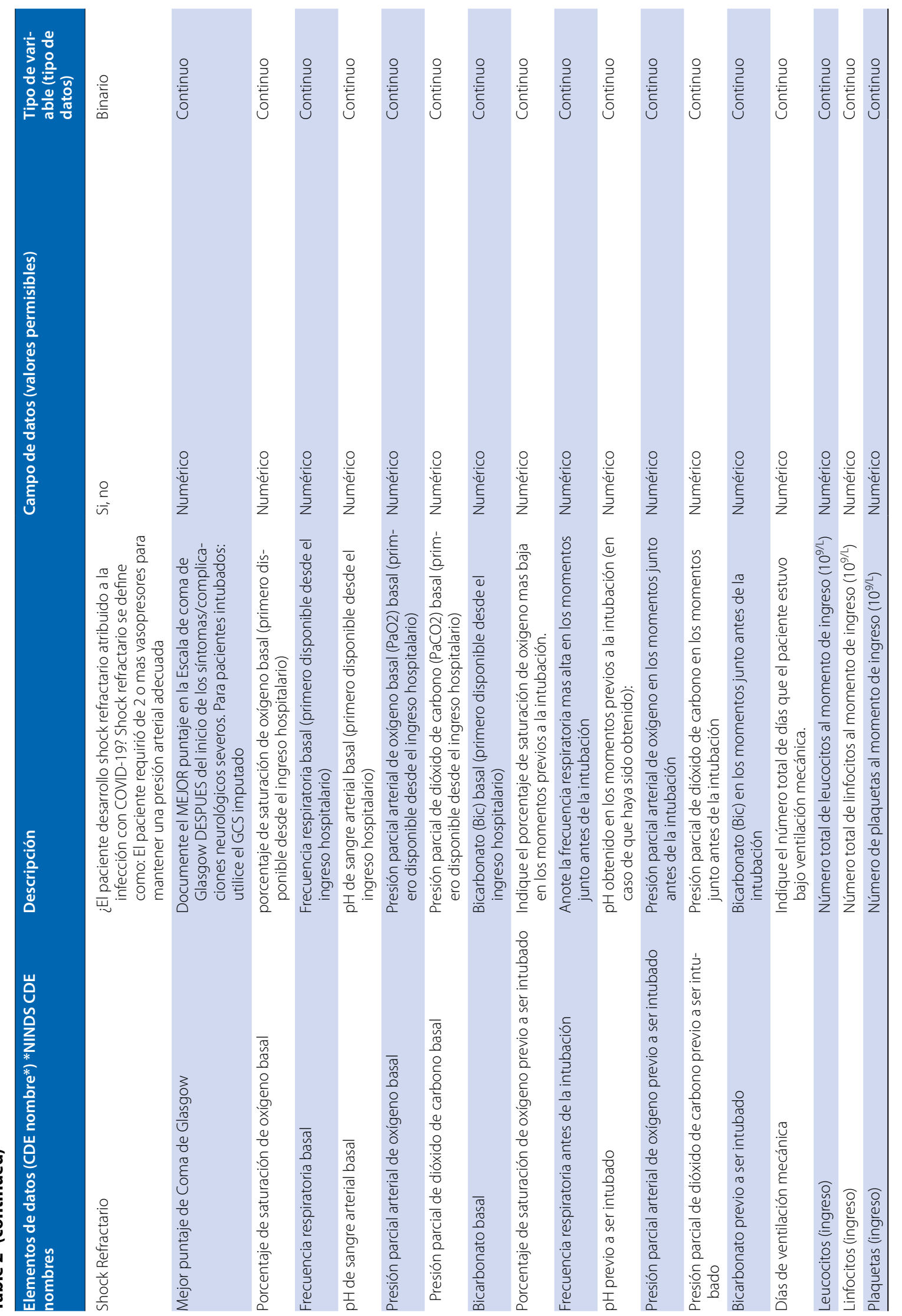




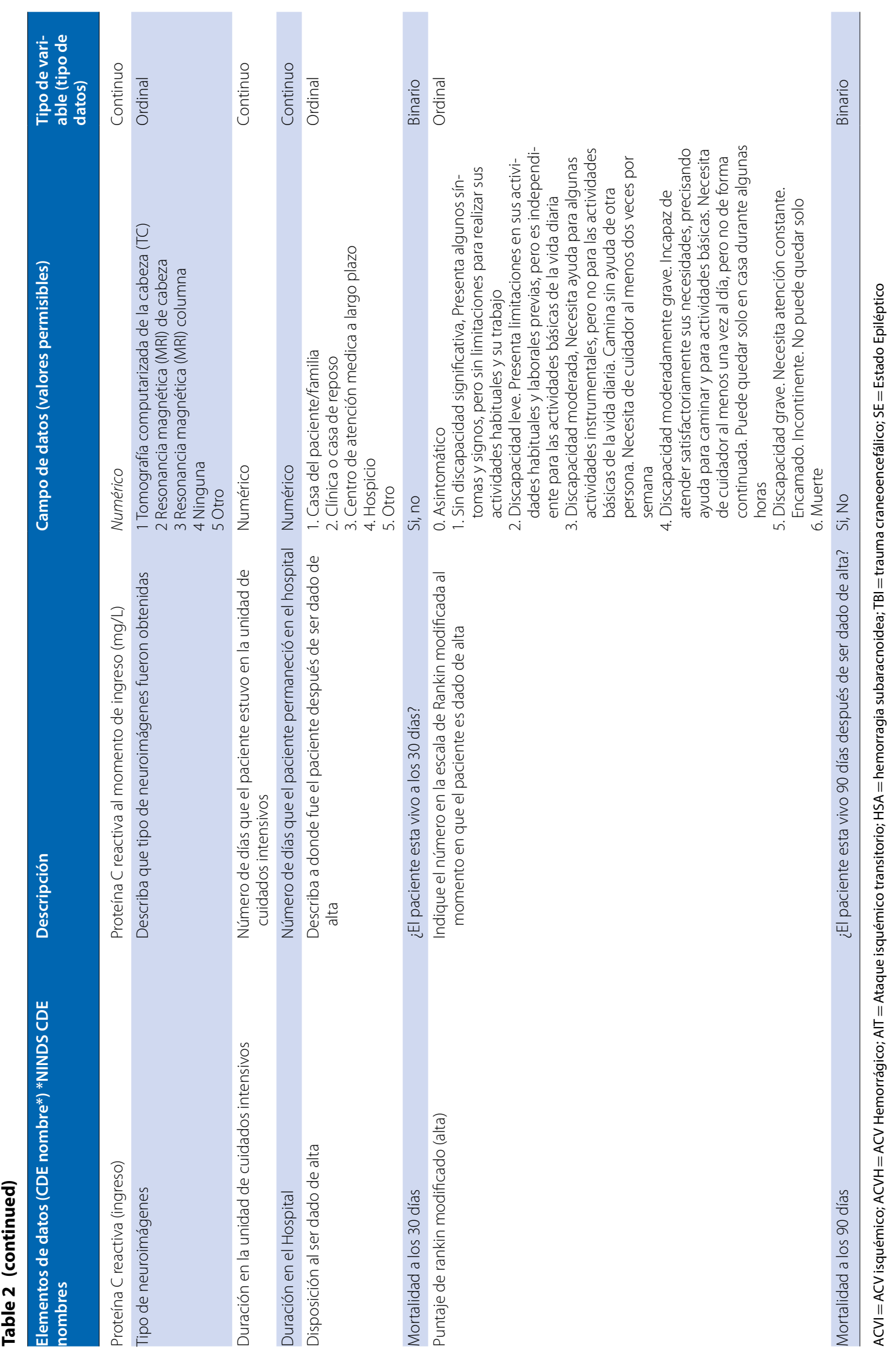




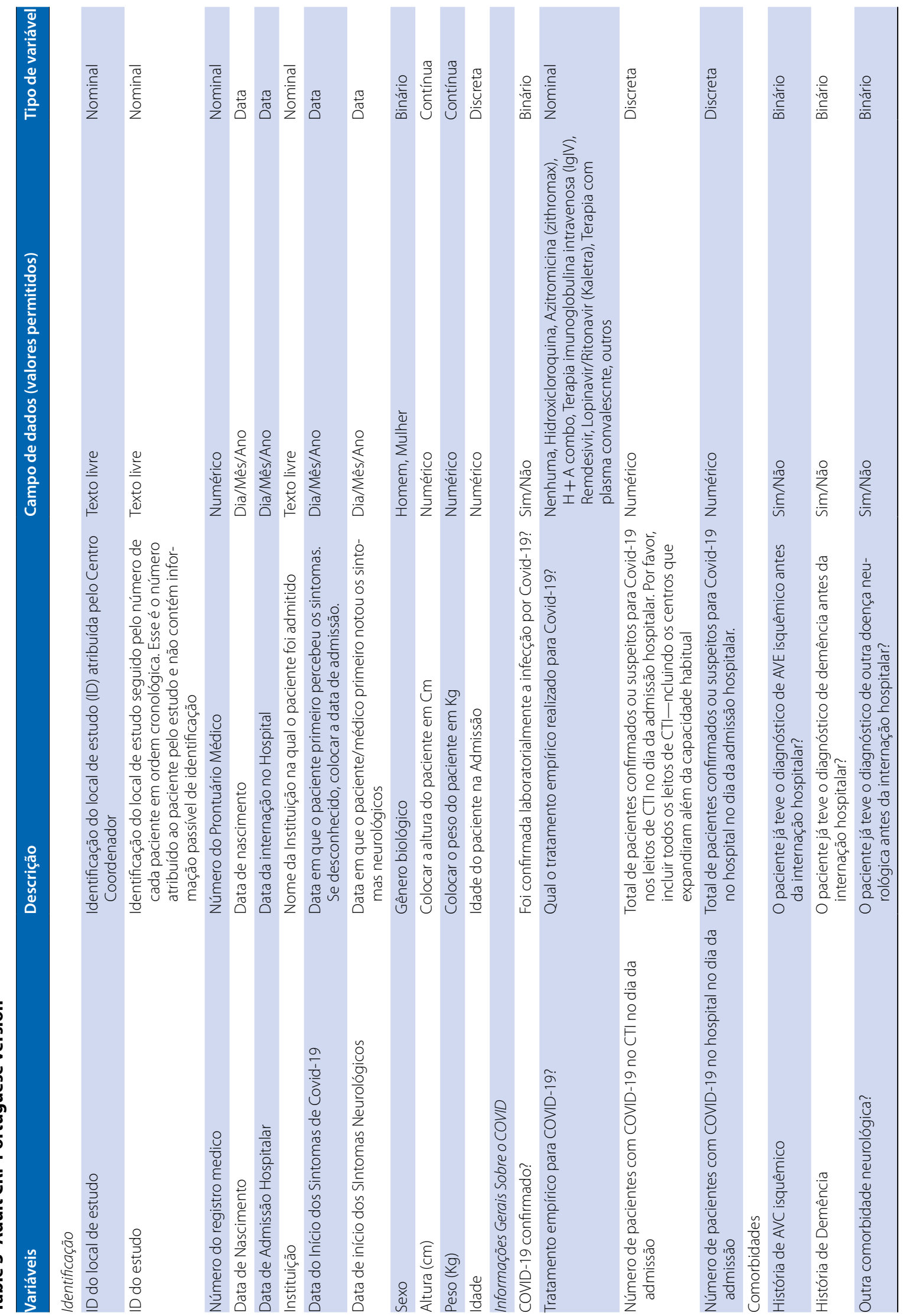




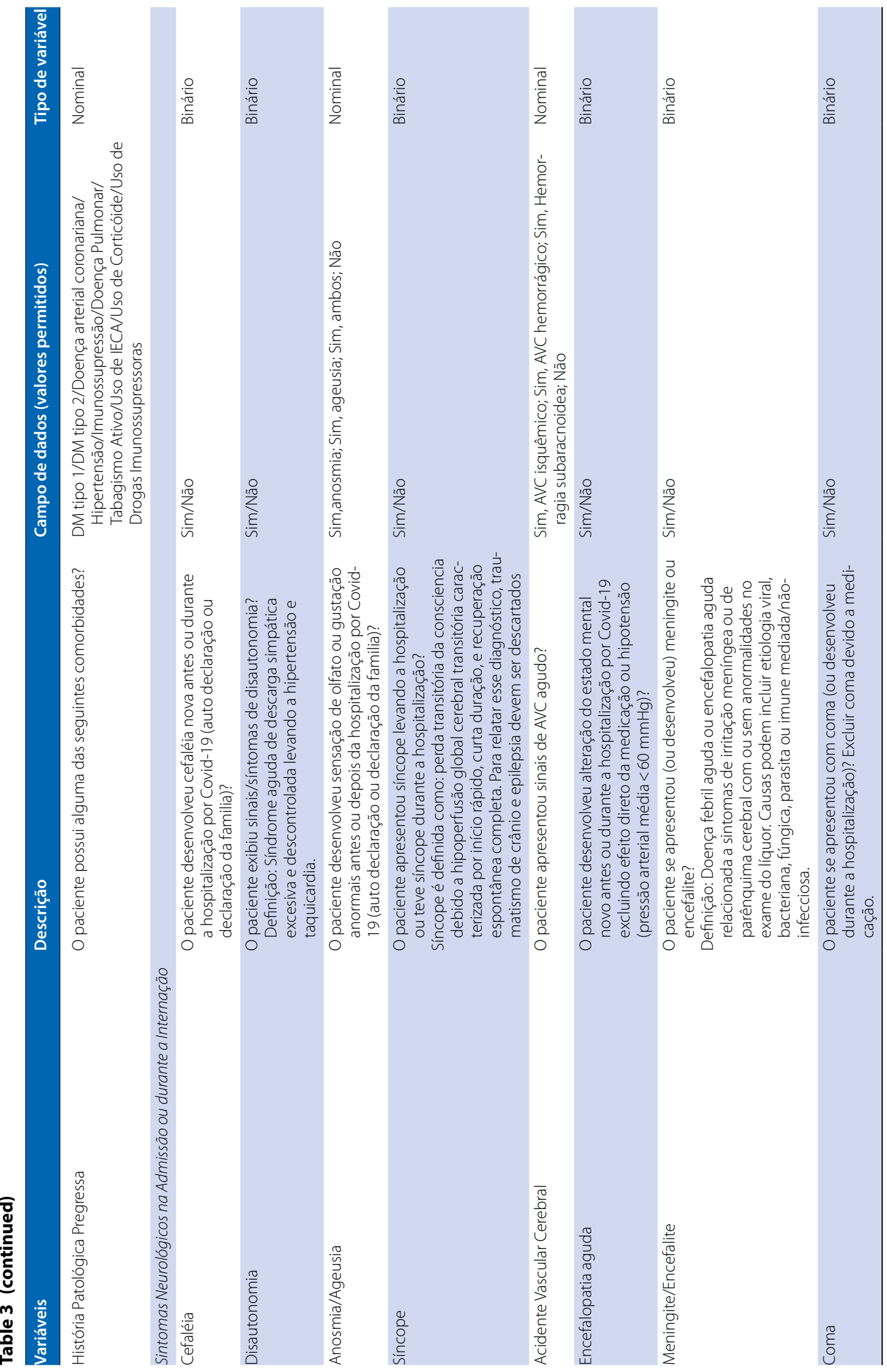









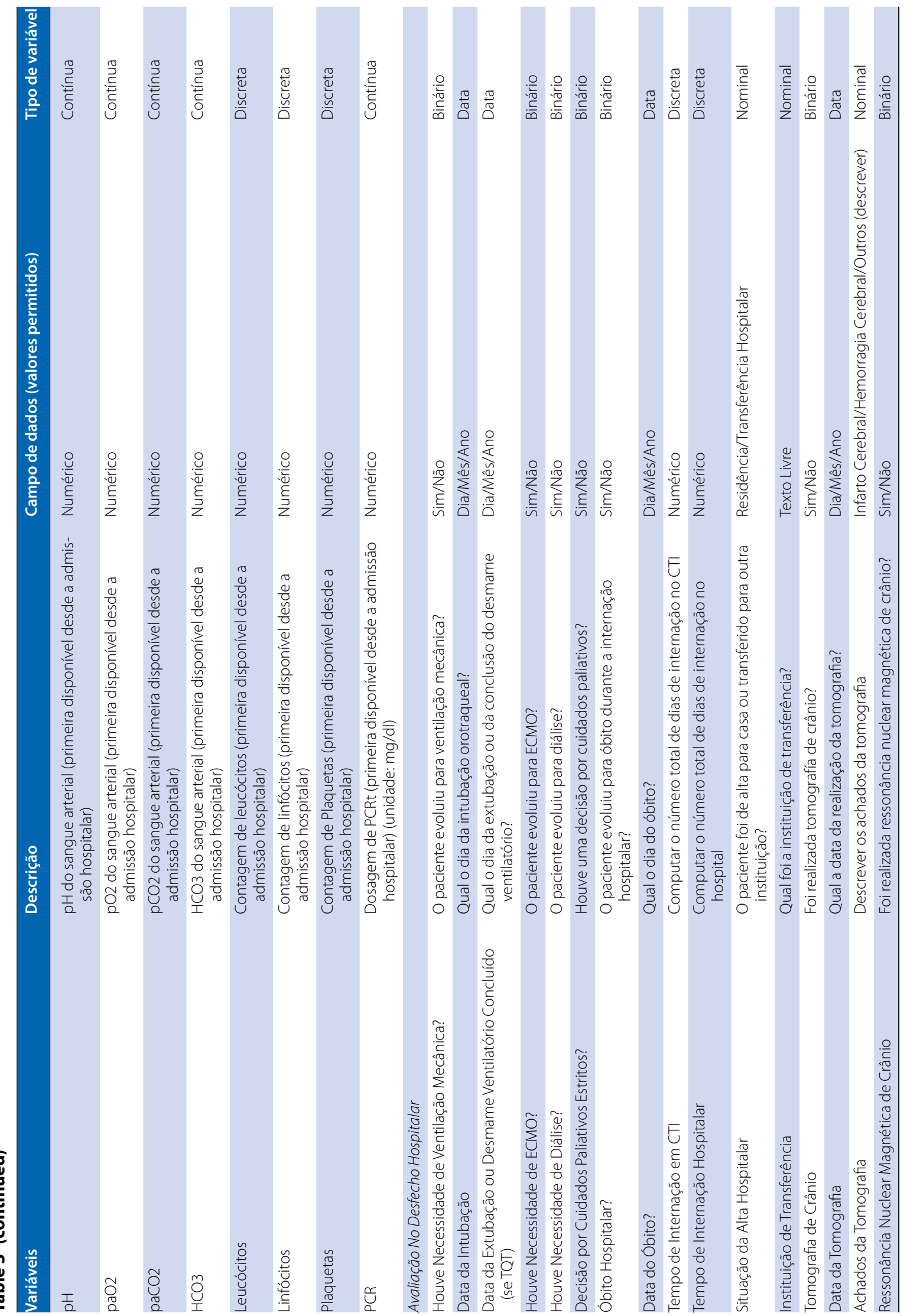




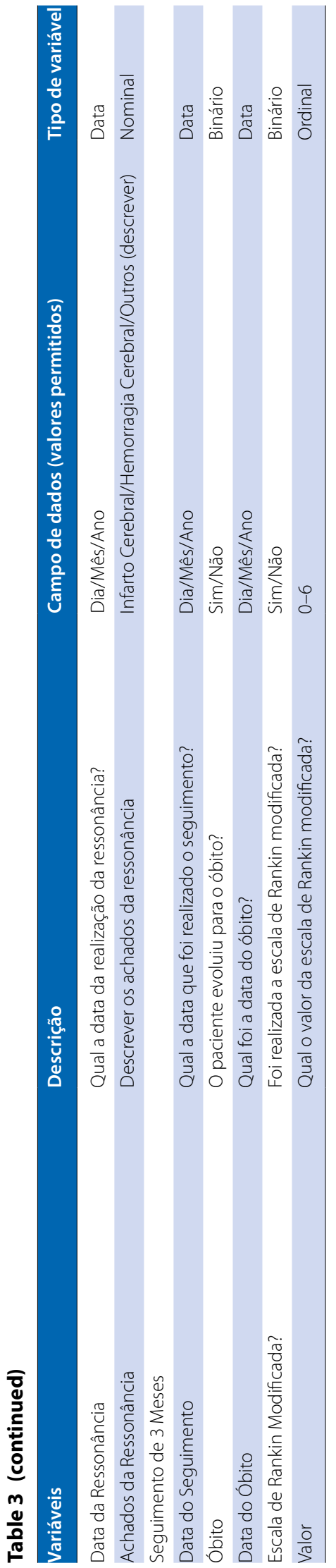

the Neurocritical Care Society (NCS) and the GCS-NeuroCOVID consortium. The GCS-NeuroCOVID Spanish data elements and CRF are developed in close collaboration with LABIC consortia. This harmonization of data elements and definitions is an important step toward harmonized data capture of COVID-19 neurological manifestations across the North, Central, and South America.

\section{Harmonization with POSSIBLE Network and Development of Adult Portuguese Version CRF}

The GCS-NeuroCOVID consortium is endorsed by and collaborates closely with the Prospective Observational Study of Subarachnoid hemorrhage and IntracereBral hemorrhage patients in Latin America (POSSIBLE) network. The POSSIBLE network was created in 2017 to investigate the epidemiology and the medical practices in hemorrhagic stroke and subarachnoid hemorrhage in 33 Latin America critical care units including 12 primary Portuguese-speaking sites in Brazil. Non-Portuguesespeaking sites include critical care units from Argentina, Bolivia, Chile, Colombia, Cuba, Equator, Paraguay, Peru, Puerto Rico, Uruguay, and Venezuela. There are three coordinating sites: Brain's Institute in Rio de Janeiro, led by CR and PK (for centers from Brazil) and Fundación Valle del Lili, and Hospital Universitário (Cali, Colombia) and Hospital de Especialidades Eugenio Espejo (Quito, Equator), led by JM and NM, respectively (for the nonPortuguese-speaking sites). All data collected are stored in a RedCap database linked to the Brain's Institute.

As soon as the COVID-19 pandemic emerged in South America, two POSSIBLE network investigators (CR and PK) developed a common database for neurological manifestations in COVID-19 patients by leveraging the existing infrastructure of POSSIBLE network in Brazil. In collaboration with the GCS-NeuroCOVID consortium, lead POSSIBLE investigators (CR and PK) harmonized the GCS-NeuroCOVID Tier 1 CDEs with existing POSSIBLE CDEs to create a single neurological COVID-19 CRF for the POSSIBLE network. They further translated all data elements and the data dictionary into Portuguese (Table 3). Some variables were adjusted due to regional heterogeneity. For example, the discharge disposition was changed to free text, because there are few long-term facilities like hospice units or long-term care units in Brazil.

\section{Development of Pediatric CRFs (English and Spanish)}

The pediatric CRF (Table 4) was approached with similar principles as the adult CRF with some intentional differences. COVID-19 infection prevalence in hospitalized children is estimated to be 9.4 and 5.4 per 100,000 in children aged $0-4$ and 5-17 years of age, respectively, 
Table 4 Pediatric case report form (CRF)

\begin{tabular}{|c|c|c|c|}
\hline Data elements & Description & $\begin{array}{l}\text { Data fields } \\
\text { (permissible } \\
\text { values) }\end{array}$ & Variable type \\
\hline Site identification (ID) & Assigned on-site ID tab & Fixed & Fixed \\
\hline Participant ID & Auto-assigned & Fixed & Fixed \\
\hline Study ID & Auto-assigned & Fixed & Fixed \\
\hline Institution/hospital & Name of institution/hospital patient is admitted to & Free text & Free text \\
\hline Academic/university hospital & Is your hospital an academic or university center? & Yes/no/unknown & Binary \\
\hline Freestanding children's hospital & Is your hospital a dedicated children's hospital? & Yes/no/unknown & Binary \\
\hline Pediatric neurocritical care service & $\begin{array}{l}\text { Does your hospital have a pediatric neurocritical care } \\
\text { service? }\end{array}$ & Yes/no/unknown & Binary \\
\hline Total pediatric hospital beds & $\begin{array}{l}\text { What is the total number of pediatric hospital beds in } \\
\text { your center? (excluding Neonatal Intensive Care Unit } \\
\text { (NICU) }\end{array}$ & Numeric & Continuous \\
\hline Total pediatric ICU beds & $\begin{array}{l}\text { What is the total number of pediatric ICU beds in your } \\
\text { center? }\end{array}$ & Free text & Continuous \\
\hline Hospital admission date & Index admission to hospital & MM/DD/year & Date \\
\hline PICU admission date & Index admission to pediatric ICU & MM/DD/year & Date \\
\hline PICU discharge date & Index discharge/transfer from pediatric ICU & MM/DD/year & Date \\
\hline Hospital discharge date & Index discharge from hospital & MM/DD/year & Date \\
\hline Total days hospital admission & $\begin{array}{l}\text { Total days of hospital admission (admission to discharge } \\
\text { from hospital) patients discharged from ED will be } \\
\text { entered as } 1 \text { day }\end{array}$ & Numeric & Continuous \\
\hline Hospital disposition & Index discharge disposition from hospital & List & Nominal \\
\hline Sex & Patient's biological sex (not self-identified gender) & List & Nominal \\
\hline Weight (kg) & Enter weight in kilograms & Free text & Continuous \\
\hline Height (cm) & Enter height in centimeters & Free text & Continuous \\
\hline Age & $\begin{array}{l}\text { Patient's age on presentation (whole numbers for chil- } \\
\text { dren } 1+\text { years and fractions for children }<1 \text { ) }\end{array}$ & Numeric & Continuous \\
\hline Race & Patient's race & List & Nominal \\
\hline Ethnicity & Patient's self-reported ethnicity & List & Nominal \\
\hline Comorbidity: neurological & Patient has a neurological comorbidity & Yes/no/unknown & Binary \\
\hline Comorbidity: cardiovascular & Patient has a cardiovascular comorbidity & Yes/no/unknown & Binary \\
\hline Comorbidity: respiratory & Patient has a pulmonary comorbidity & Yes/no/unknown & Binary \\
\hline Comorbidity: renal or urologic & Patient has a renal or urologic comorbidity & Yes/no/unknown & Binary \\
\hline Comorbidity: gastrointestinal & Patient has gastrointestinal comorbidity & Yes/no/unknown & Binary \\
\hline Comorbidity: hematologic or immunologic & Patient has a hematologic or immunologic comorbidity & Yes/no/unknown & Binary \\
\hline Comorbidity: metabolic & Patient has a metabolic comorbidity & Yes/no/unknown & Binary \\
\hline Comorbidity: congenital or genetic defect & Patient has a congenital or genetic comorbidity & Yes/no/unknown & Binary \\
\hline Comorbidity: malignancy & Patient has a malignancy comorbidity & Yes/no/unknown & Binary \\
\hline Comorbidity: premature or neonatal & Patient has a premature or neonatal comorbidity & Yes/no/unknown & Binary \\
\hline Comorbidity: technology dependence & Patient has a technology dependence comorbidity & Yes/no/unknown & Binary \\
\hline Comorbidity: transplantation & Patient has a transplantation comorbidity & Yes/no/unknown & Binary \\
\hline Comorbidity: other, nonneurological & Patient has another, nonneurological comorbidity & Yes/no/unknown & Binary \\
\hline COVID diagnosis PCR test & PCR test positive & Yes/no/unknown & Binary \\
\hline COVID diagnosis PCR test date & PCR test positive date & MM/DD/year & Date \\
\hline COVID diagnosis presumed positive & $\begin{array}{l}\text { Patient presumed (not tested) positive due to positive } \\
\text { close contacts (NOT simply person under investiga- } \\
\text { tion) }\end{array}$ & Yes/no/unknown & Binary \\
\hline COVID diagnosis presumed positive date & $\begin{array}{l}\text { Patient presumed (not tested) positive due to positive } \\
\text { close contacts (NOT simply person under investiga- } \\
\text { tion) date }\end{array}$ & MM/DD/year & Date \\
\hline COVID diagnosis antibody test & Antibody test positive & Yes/no/unknown & Binary \\
\hline COVID diagnosis antibody test date & Antibody test positive date & MM/DD/year & Date \\
\hline
\end{tabular}


Table 4 (continued)

\section{Data elements \\ (a)}

Date of ANY COVID symptom onset

Date of neurological symptom onset
Headache
Date of headache onset
Sympathetic storming/dysautonomia
Date of storming/dysautonomia onset
Anosmia
Date of anosmia onset
Ageusia
Date of ageusia onset
Vision impairment
Date of vision impairment onset
Syncope
Date of syncope onset
Stroke
Date of stoke onset
Acute encephalopathy (altered mental status, lethargy,
or drowsiness)
Date of acute encephalopathy onset
Cardiac arrest
Date of cardiac arrest onset
Meningitis/encephalitis
Date of meningitis/encephalitis onset
Coma

Date of coma onset

Clinical seizures/status epilepticus

Date of clinical seizure/status epilepticus onset

Numbness

Date of numbness onset

Weakness

Date of weakness onset

Neuropathy

Date of neuropathy onset

Paresthesia

Date of paresthesia onset

Myelopathy

Date of myelopathy onset

Dizziness

Date of dizziness onset

Ataxia

Date of ataxia onset

Other neurological manifestations, describe

Date of other neurological manifestations onset

Fever
Description

Data fields

(permissible

values)

Date patient noticed symptom first. If unknown/no history, please enter admission date

Date patient first developed neurological symptoms

Did the patient report headache?

Date first noted

MM/DD/year

Variable type

Variable type

Did the patient exhibit signs/symptoms of sympathetic Yes/no/unknown Binary storming?

Date first noted

Did patient report abnormal smell?

Date first noted

MM/DD/YEAR Date

Yes/no/unknown Binary

MM/DD/year Date

Did patient report either loss of taste or abnormal taste?

Date first noted

Did patient report abnormal vision?

Date first noted

Did the patient develop syncope?

Date first noted

Did the patient have an acute stroke?

Date first noted

MM/DD/year Date

Yes/no/unknown Binary

MM/DD/year Date

Yes/no/unknown Binary

MM/DD/year Date

Yes/no/unknown Binary

MM/DD/year Date

Yes/no/unknown Binary

MM/DD/year Date

Drop down Nominal

MM/DD/year Date

Did patient develop new onset altered mental status, $\quad$ Yes/no/unknown Binary lethargy, or drowsiness?

Date first noted MM/DD/year Date

Did patient develop cardiac arrest? $\quad$ Yes/no/unknown Binary

Date first noted MM/DD/year Date

Did patient have meningitis or encephalitis? Yes/no/unknown Binary

Date first noted. MM/DD/year Date

Did patient develop coma (by examination)? Exclude Yes/no/unknown Binary coma due to medication. Coma definition: unarousable to noxious stimuli, no eye tracking or purposeful movement, no spontaneous eye opening

Date first noted

MM/DD/year Date

Did patient develop clinical seizure/status epilepticus?

Date first noted

Did patient develop numbness?

Date first noted

Did patient develop weakness?

Date first noted

Did patient develop neuropathy?

Date first noted

Did patient develop paresthesia?

Date first noted

Did patient show signs of myelopathy?

Date first noted

Did patient report dizziness?

Date first noted

Did patient show signs of ataxia?

Date first noted

If the patient exhibited other neurological manifestations, please describe

Date first noted

Yes/no/unknown Binary

MM/DD/year Date

Yes/no/unknown Binary

MM/DD/year Date

Yes/no/unknown Binary

MM/DD/year Date

Yes/no/unknown Binary

MM/DD/year Date

Yes/no/unknown Binary

MM/DD/year Date

Yes/no/unknown Binary

MM/DD/year Date

Yes/no/unknown Binary

MM/DD/year Date

Yes/no/unknown Binary

MM/DD/year Date

Free text Nominal

Did patient have fever?
MM/DD/year Date

Yes/no/unknown Binary 
Table 4 (continued)

\begin{tabular}{|c|c|c|c|}
\hline Data elements & Description & $\begin{array}{l}\text { Data fields } \\
\text { (permissible } \\
\text { values) }\end{array}$ & Variable type \\
\hline Date of fever onset & Date first noted & MM/DD/year & Date \\
\hline Cough & Did patient have cough? & Yes/no/unknown & Binary \\
\hline Date of cough onset & Date first noted & MM/DD/year & Date \\
\hline Delirium & Did patient have delirium? & Yes/no/unknown & Binary \\
\hline Date of delirium onset & Date first noted & MM/DD/year & Date \\
\hline How was delirium diagnosed? & Delirium tool (name it) or clinical & Free text & Nominal \\
\hline Anorexia & Did patient have anorexia? & Yes/no/unknown & Binary \\
\hline Date of anorexia onset & Date first noted & MM/DD/year & Date \\
\hline Diarrhea & Did patient have diarrhea? & Yes/no/unknown & Binary \\
\hline Date of diarrhea onset & Date first noted & MM/DD/year & Date \\
\hline Throat pain & Did patient have throat pain? & Yes/no/unknown & Binary \\
\hline Date of throat pain onset & Date first noted & MM/DD/year & Date \\
\hline Abdominal pain & Did patient have abdominal pain? & Yes/no/unknown & Binary \\
\hline Date of abdominal pain onset & Date first noted & MM/DD/year & Date \\
\hline Electroencephalography (EEG) completed & Was an EEG performed? & Yes/no/unknown & Binary \\
\hline EEG date & Date of first EEG & MM/DD/year & Date \\
\hline EEG results & EEG results & List & Binary \\
\hline EEG final read & Final read of first EEG & Free text & Free text \\
\hline Brain computed tomography (CT) & Was a brain CT performed? & Yes/no/unknown & Binary \\
\hline Date of brain $\mathrm{CT}$ & Date of first brain CT & MM/DD/year & Date \\
\hline Brain CT results & Results of first brain CT & Drop-down & Nominal \\
\hline Brain CT final read & Final read of first brain $\mathrm{CT}$ & Free text & Free text \\
\hline Brain magnetic resonance imaging (MRI) & Was a brain MRI performed? & Yes/no/unknown & Binary \\
\hline Date of brain MRI & Date of first brain MRI & MM/DD/year & Date \\
\hline Brain MRI results & Results of first brain MRI & List & Binary \\
\hline Brain MRI final read & Final read of first brain MRI & Free text & Free text \\
\hline Cerebrospinal fluid (CSF) testing & Was CSF tested? & Yes/no/unknown & Binary \\
\hline Date of first CSF testing & Date of first CSF studies & MM/DD/year & Date \\
\hline CSF white blood cell (WBC) count & CSF WBC count & Numeric & Continuous \\
\hline CSF red blood cell (RBC) count & CSF RBC count & Numeric & Continuous \\
\hline CSF glucose & CSF glucose mg/dl & Numeric & Continuous \\
\hline CSF protein & CSF protein mg/dl & Numeric & Continuous \\
\hline CSF culture (viral and bacterial) & CSF culture results & Free text & Free text \\
\hline CSF polymerase chain reaction (PCR) & CSF PCR results—viral and other & Free text & Free text \\
\hline CSF COVID testing & CSF COVID testing & List & Binary \\
\hline CSF opening pressure & CSF opening pressure in $\mathrm{cm} \mathrm{H} 2 \mathrm{O}$ & Numeric & Continuous \\
\hline CSF other results & $\begin{array}{l}\text { CSF other results (antibody, oligoclonal bands, inflam- } \\
\text { matory molecules such as IL-6) }\end{array}$ & Free text & Free text \\
\hline Extracorporeal membrane oxygenation (ECMO) & $\begin{array}{l}\text { Did the patient require ECMO therapy while hospital- } \\
\text { ized? }\end{array}$ & Yes/no/unknown & Binary \\
\hline ECMO days & How many days was the patient on ECMO? & Numeric & Continuous \\
\hline Extracorporeal cardiopulmonary resuscitation (ECPR) & Was the patient placed on ECMO DURING ACTIVE CPR? & Yes/no/unknown & Binary \\
\hline Date of ECPR & Date first noted & MM/DD/year & Date \\
\hline Dialysis/continuous renal replacement therapy (CRRT) & $\begin{array}{l}\text { Did the patient develop acute kidney injury requiring } \\
\text { dialysis/continuous renal replacement therapy }\end{array}$ & Yes/no/unknown & Binary \\
\hline Dialysis/CRRT days & How many days was the patient on dialysis/CRRT? & Numeric & Continuous \\
\hline Invasive mechanical ventilation & $\begin{array}{l}\text { Did patient require intubation and mechanical ventila- } \\
\text { tion during critical care admission }\end{array}$ & Yes/no/unknown & Binary \\
\hline
\end{tabular}


Table 4 (continued)

\begin{tabular}{|c|c|c|c|}
\hline Data elements & Description & $\begin{array}{l}\text { Data fields } \\
\text { (permissible } \\
\text { values) }\end{array}$ & Variable type \\
\hline Invasive mechanical ventilation days & $\begin{array}{l}\text { How many days was the patient on invasive mechanical } \\
\text { ventilation? }\end{array}$ & Numeric & Continuous \\
\hline Noninvasive mechanical ventilation & $\begin{array}{l}\text { Did patient require noninvasive mechanical ventilation } \\
\text { during critical care admission }\end{array}$ & Yes/no/unknown & Binary \\
\hline Noninvasive mechanical ventilation days & $\begin{array}{l}\text { How many days was the patient on noninvasive } \\
\text { mechanical ventilation? }\end{array}$ & Numeric & Continuous \\
\hline Intracranial pressure (ICP) monitor & Did the patient have an ICP placed? & Yes/no/unknown & Binary \\
\hline ICP device type & What kind of ICP monitor was placed? & Drop-down & Nominal \\
\hline ICP monitor: date placed & Day of ICP monitor placement & MM/DD/year & Date \\
\hline ICP monitor: total days & If yes, how many days? & Numeric & Continuous \\
\hline ICP monitor: initial ICP & Initial intracranial pressure, $\mathrm{mmHg}$ & Numeric & Continuous \\
\hline ICP monitor: ICP peak & $\begin{array}{l}\text { Peak intracranial pressure (record ICP values that were } \\
\text { sustained }>2 \mathrm{~min} \text { ) }\end{array}$ & Numeric & Continuous \\
\hline ICP monitor: day of ICP peak & Day of peak ICP & MM/DD/year & Date \\
\hline ICP monitor: cerebral perfusion pressure (CPP) low & Lowest CPP & Numeric & Continuous \\
\hline ICP monitor: day of CPP low & Day of lowest CPP & MM/DD/year & Date \\
\hline Cause of death & $\begin{array}{l}\text { What was the cause of in-hospital death if the patient } \\
\text { died? }\end{array}$ & Free text & Free text \\
\hline Pediatric Index of Mortality (PIM) [30] & $\begin{array}{l}\text { PIM score on hospital admission (see "Scoring Guides" } \\
\text { tab for scoring calculator) }\end{array}$ & \# percent & Continuous \\
\hline Glasgow Coma Score (GCS) & $\begin{array}{l}\text { GCS on hospital admission (if no neuromuscular block- } \\
\text { ade) }\end{array}$ & $3-15$ & Ordinal \\
\hline Pediatric Logistic Organ Dysfunction-2 (PELOD) [29] & $\begin{array}{l}\text { PELOD score on hospital admission (see "Scoring Guides" } \\
\text { tab for scoring calculator) }\end{array}$ & Numeric & Continuous \\
\hline WBC & Enter WBC to two decimal points & Numeric & Continuous \\
\hline Lymphocytes & Enter absolute lymphocytes at admission & Numeric & Continuous \\
\hline Lymphocytes-lowest & $\begin{array}{l}\text { Enter lowest absolute lymphocyte count during hospi- } \\
\text { talization }\end{array}$ & Numeric & Continuous \\
\hline Lymphocytes_-date lowest & Date of laboratory value & MM/DD/year & Date \\
\hline Platelets & Enter platelets at admission & Numeric & Continuous \\
\hline Platelets_lowest & Enter lowest platelet count during hospitalization & Numeric & Continuous \\
\hline Platelets_date lowest & Date of laboratory value & MM/DD/year & Date \\
\hline Sodium & Enter blood sodium level $\mathrm{mMol} / \mathrm{L}$ on admission & Numeric & Continuous \\
\hline Hemoglobin & Enter hemoglobin level $\mathrm{g} / \mathrm{dL}$ on admission & Numeric & Continuous \\
\hline Interleukin (IL-6) (first) & Enter IL-6 if done & Numeric & Continuous \\
\hline IL-6 (first) date & Date of laboratory value & MM/DD/year & Date \\
\hline C-reactive protein (CRP) & Enter first CRP mg/dl & Numeric & Continuous \\
\hline CRP_highest & Enter the highest CRP during admission & Numeric & Continuous \\
\hline CRP_highest date & Date of laboratory value & MM/DD/year & Date \\
\hline Ferritin & Enter first ferritin $\mathrm{ng} / \mathrm{ml}$ & Numeric & Continuous \\
\hline Ferritin—highest & Enter highest ferritin during admission & Numeric & Continuous \\
\hline Ferritin—highest date & Date of laboratory value & MM/DD/year & Date \\
\hline Procalcitonin & Enter first procalcitonin, ng/mL & Numeric & Continuous \\
\hline Procalcitonin-highest & Enter highest the procalcitonin $\mathrm{ng} / \mathrm{mL}$ during admission & Numeric & Continuous \\
\hline Procalcitonin — the highest date & Date of laboratory value & MM/DD/year & Date \\
\hline Fibrinogen & Enter fibrinogen on ADMIT, mg/dL & Numeric & Continuous \\
\hline Fibrinogen—lowest & Enter lowest fibrinogen during admission, mg/dl & Numeric & Continuous \\
\hline Fibrinogen — the lowest date & Date of laboratory value & MM/DD/year & Date \\
\hline Alanine aminotransferase (ALT) & Enter the first ALT, Intl U/L & Numeric & Continuous \\
\hline ALT_highest & Enter the highest ALT during admission, Intl U/L & Numeric & Continuous \\
\hline
\end{tabular}


Table 4 (continued)

\begin{tabular}{|c|c|c|c|}
\hline Data elements & Description & $\begin{array}{l}\text { Data fields } \\
\text { (permissible } \\
\text { values) }\end{array}$ & Variable type \\
\hline ALT_the highest date & Date of laboratory value & MM/DD/year & Date \\
\hline Aspartate aminotransferase (AST) & Enter the first AST & Numeric & Continuous \\
\hline AST_highest & Enter the highest AST during admission & Numeric & Continuous \\
\hline AST_-the highest date & Date of laboratory value & MM/DD/year & Date \\
\hline Prothrombin (PT) & Enter the first PT & Numeric & Continuous \\
\hline PT-highest & Enter the highest PT during admission & Numeric & Continuous \\
\hline PT_-the highest date & Date of laboratory value & MM/DD/year & Date \\
\hline Partial thromboplastin time (PTT) & Enter the first PTT & Numeric & Continuous \\
\hline PTT—highest & Enter the highest PTT during admission & Numeric & Continuous \\
\hline PTT_the highest date & Date of laboratory value & MM/DD/year & Date \\
\hline International normalized ratio (INR) & Enter the first INR & Numeric & Continuous \\
\hline INR-highest & Enter the highest INR during admission & Numeric & Continuous \\
\hline INR—-the highest date & Date of laboratory value & MM/DD/year & Date \\
\hline D-Dimer & Enter the first D-dimer & Numeric & Continuous \\
\hline D-dimer-highest & Enter the highest D-dimer during admission & Numeric & Continuous \\
\hline D-dimer-the highest date & Date of laboratory value & MM/DD/year & Date \\
\hline Positive blood culture & Did the patient have a positive blood culture & Yes/no/unknown & Binary \\
\hline Blood culture date & Date blood culture sent & MM/DD/year & Date \\
\hline Blood culture results & Results of positive blood culture & Free text & Free text \\
\hline Positive respiratory culture & Did the patient have a positive respiratory culture & Yes/no/unknown & Binary \\
\hline Respiratory culture date & Date respiratory culture sent & MM/DD/year & Date \\
\hline Respiratory culture results & Results of positive respiratory culture & Free text & Free text \\
\hline Respiratory viral panel (non-COVID-19) & $\begin{array}{l}\text { Was respiratory viral panel sent for non-COVID-19 } \\
\text { viruses? }\end{array}$ & Yes/no/unknown & Binary \\
\hline Respiratory viral panel date & Date respiratory viral panel sent & MM/DD/year & Date \\
\hline Respiratory viral panel results & Results of respiratory viral panel & Free text & Free text \\
\hline Other coinfection detected? & List other coinfections (organisms, sites, dates) & Free text & Free text \\
\hline Lowest arterial blood gas (ABG) pH (intubated) & Enter worst ABG pH while intubated if done & Numeric & Continuous \\
\hline Lowest ABG pH date & Date of laboratory value & MM/DD/year & Date \\
\hline Lowest ABG pO2 (Intubated) & Enter the lowest ABG pO2 while intubated if done & Numeric & Continuous \\
\hline Lowest ABG pO2 Date & Date of laboratory value & MM/DD/year & Date \\
\hline Highest Oxygenation Index (OI) (intubated) & $\begin{array}{l}\text { Enter Ol associated with worst } \mathrm{pO} 2 \text { while intubated } \\
\text { if } \mathrm{ABG} \text { done (https://www.mdcalc.com/oxygenatio } \\
\text { n-index) }\end{array}$ & Numeric & Continuous \\
\hline Highest Oxygenation Index (OI) (Intubated) date & Date of laboratory value & MM/DD/year & Date \\
\hline Highest ABG PCO2 (intubated) & Enter the highest $\mathrm{ABG}$ pCO2 while intubated if done & Numeric & Continuous \\
\hline Highest ABG PCO2 (intubated) date & Date of laboratory value & MM/DD/year & Date \\
\hline Empiric COVID-19 treatment \#1 & $\begin{array}{l}\text { Enter the first medication used for empiric COVID-19 } \\
\text { treatment }\end{array}$ & Free text & Free text \\
\hline List "other" empiric COVID treatment \#1 & List other empiric COVID-19 treatments & Free text & Free text \\
\hline Empiric COVID treatment \#1 date & Start date of empiric COVID treatment \#1 & MM/DD/year & Date \\
\hline Dosing and duration for COVID-19 treatment \#1 & $\begin{array}{l}\text { Enter dosing for any medication \#1 used for empiric } \\
\text { COVID-19 treatment }\end{array}$ & Free text & Free text \\
\hline Empiric COVID-19 treatment \#2 & $\begin{array}{l}\text { Enter the second medication used for empiric COVID-19 } \\
\text { treatment }\end{array}$ & Free text & Free text \\
\hline List "other" empiric COVID treatment \#2 & List other empiric COVID-19 treatments & Free text & Free text \\
\hline Empiric COVID treatment \#2 date & Start date of empiric COVID treatment \#2 & MM/DD/year & Date \\
\hline Dosing and duration for COVID-19 treatment \#2 & $\begin{array}{l}\text { Enter dosing for any medication \#2 used for empiric } \\
\text { COVID-19 treatment }\end{array}$ & Free text & Free text \\
\hline
\end{tabular}


Table 4 (continued)

\begin{tabular}{|c|c|c|c|}
\hline Data elements & Description & $\begin{array}{l}\text { Data fields } \\
\text { (permissible } \\
\text { values) }\end{array}$ & Variable type \\
\hline Empiric COVID-19 treatment \#3 & $\begin{array}{l}\text { Enter the third medication used for empiric COVID-19 } \\
\text { treatment }\end{array}$ & Free text & Free text \\
\hline List "other" empiric COVID treatment \#3 & List other empiric COVID-19 treatments & Free text & Free text \\
\hline Empiric COVID treatment \#3 date & Start date of empiric COVID treatment \#3 & MM/DD/year & Date \\
\hline Dosing and duration for COVID-19 treatment \#3 & $\begin{array}{l}\text { Enter dosing for any medication \#3 used for empiric } \\
\text { COVID-19 treatment }\end{array}$ & Free text & Free text \\
\hline Empiric COVID-19 treatment \#4 & $\begin{array}{l}\text { Enter 4th medication used for empiric COVID-19 treat- } \\
\text { ment }\end{array}$ & Free text & Free text \\
\hline List "other" empiric COVID treatment \#4 & List other empiric COVID-19 treatments & Free text & Free text \\
\hline Empiric COVID treatment \#4 date & Start date of empiric COVID treatment \#4 & MM/DD/year & Date \\
\hline Dosing and duration for COVID-19 treatment \#4 & $\begin{array}{l}\text { Enter dosing for any medication \#4 used for empiric } \\
\text { COVID-19 treatment }\end{array}$ & Free text & Free text \\
\hline Empiric COVID-19 treatment \#5 & $\begin{array}{l}\text { Enter } 5 \text { th medication used for empiric COVID-19 treat- } \\
\text { ment }\end{array}$ & Free text & Free text \\
\hline List "other" empiric COVID treatment \#5 & Start date of empiric COVID treatment \#5 & MM/DD/year & Date \\
\hline Empiric COVID treatment \#5 date & $\begin{array}{l}\text { Enter dosing for any medication \#5 used for empiric } \\
\text { COVID-19 treatment }\end{array}$ & Free text & Free text \\
\hline Dosing and duration for COVID-19 treatment \#5 & $\begin{array}{l}\text { enter dosing for any medication \#5 used for empiric } \\
\text { COVID-19 treatment }\end{array}$ & Free text & Free text \\
\hline $\begin{array}{l}\text { Multisystem inflammatory Syndrome (MIS-C) related to } \\
\text { COVID-19 [31] }\end{array}$ & Did patient have this syndrome diagnosed? & Yes/no/unknown & Binary \\
\hline Multisystem inflammatory syndrome date & Date first noted & MM/DD/year & Date \\
\hline Empiric MIS-C treatment \#1 & $\begin{array}{l}\text { Enter the first therapy used for empiric syndrome treat- } \\
\text { ment }\end{array}$ & Free text & Free text \\
\hline Empiric MIS-C treatment \#1 date & $\begin{array}{l}\text { Enter the first therapy used for empiric syndrome treat- } \\
\text { ment start date }\end{array}$ & MM/DD/year & Date \\
\hline Dosing and duration for MIS-C treatment \#1 & $\begin{array}{l}\text { Enter dosing for any medication \#1 used for empiric } \\
\text { syndrome treatment }\end{array}$ & Free text & Free text \\
\hline Empiric MIS-C treatment \#2 & $\begin{array}{l}\text { Enter the second medication used for empiric syndrome } \\
\text { treatment }\end{array}$ & Free text & Free text \\
\hline Empiric MIS-C treatment \#2 date & $\begin{array}{l}\text { Enter the second therapy used for empiric syndrome } \\
\text { treatment start date }\end{array}$ & MM/DD/year & Date \\
\hline Dosing and duration for MIS-C treatment \#2 & $\begin{array}{l}\text { Enter dosing for any medication \#2 used for empiric } \\
\text { syndrome treatment }\end{array}$ & Free text & Free text \\
\hline Empiric MIS-C treatment \#3 & $\begin{array}{l}\text { Enter the third medication used for empiric syndrome } \\
\text { treatment }\end{array}$ & Free text & Free text \\
\hline Empiric MIS-C treatment \#3 date & $\begin{array}{l}\text { Enter the third therapy used for empiric syndrome treat- } \\
\text { ment start date }\end{array}$ & MM/DD/year & Date \\
\hline Dosing and duration for MIS-C treatment \#3 & $\begin{array}{l}\text { Enter dosing for any medication \#3 used for empiric } \\
\text { syndrome treatment }\end{array}$ & Free text & Free text \\
\hline Empiric MIS-C treatment \#4 & $\begin{array}{l}\text { Enter the fourth medication used for empiric syndrome } \\
\text { treatment }\end{array}$ & Free text & Free text \\
\hline Empiric MIS-C treatment \#4 date & $\begin{array}{l}\text { Enter the fourth therapy used for empiric syndrome } \\
\text { treatment start date }\end{array}$ & MM/DD/year & Date \\
\hline Dosing and duration for MIS-C treatment \#4 & $\begin{array}{l}\text { Enter dosing for any medication \#4 used for empiric } \\
\text { syndrome treatment }\end{array}$ & Free text & Free text \\
\hline Empiric MIS-C treatment \#5 & $\begin{array}{l}\text { Enter the fifth medication used for empiric syndrome } \\
\text { treatment }\end{array}$ & Free text & Free text \\
\hline Empiric MIS-C treatment \#5 date & $\begin{array}{l}\text { Enter the fifth therapy used for empiric syndrome treat- } \\
\text { ment start date }\end{array}$ & MM/DD/year & Date \\
\hline Dosing and duration for MIS-C treatment \#5 & $\begin{array}{l}\text { Enter dosing for any medication \#5 used for empiric } \\
\text { syndrome treatment }\end{array}$ & Free text & Free text \\
\hline
\end{tabular}


Table 4 (continued)

\begin{tabular}{|c|c|c|c|}
\hline Data elements & Description & $\begin{array}{l}\text { Data fields } \\
\text { (permissible } \\
\text { values) }\end{array}$ & Variable type \\
\hline $\begin{array}{l}\text { Baseline (preadmission) pediatric cerebral performance } \\
\text { category (PCPC) [27] }\end{array}$ & $\begin{array}{l}\text { Enter baseline pediatric cerebral performance category } \\
\text { (assign retrospectively) (see "Scoring Guides" tab for } \\
\text { scoring information) }\end{array}$ & Numeric & Ordinal \\
\hline Hospital admission PCPC & $\begin{array}{l}\text { Enter admission pediatric cerebral performance cate- } \\
\text { gory (see "Scoring Guides" tab for scoring information) }\end{array}$ & Numeric & Ordinal \\
\hline Hospital discharge PCPC & $\begin{array}{l}\text { Enter discharge pediatric cerebral performance category } \\
\text { (see "Scoring Guides" tab for scoring information) }\end{array}$ & Numeric & Ordinal \\
\hline Baseline (preadmission) functional status scale (FSS) [18] & $\begin{array}{l}\text { Enter baseline functional status scale (see "Scoring } \\
\text { Guides" tab for scoring information) }\end{array}$ & Numeric & Ordinal \\
\hline Hospital admission FSS & $\begin{array}{l}\text { Enter admission functional status scale (see "Scoring } \\
\text { Guides" tab for scoring information) }\end{array}$ & Numeric & Ordinal \\
\hline Hospital discharge FSS & $\begin{array}{l}\text { Enter discharge functional status scale (see "Scoring } \\
\text { Guides" tab for scoring information) }\end{array}$ & Numeric & Ordinal \\
\hline Physical therapy consult & $\begin{array}{l}\text { Did the patient have a physical therapy consultation in } \\
\text { the hospital? }\end{array}$ & Yes/no/unknown & Binary \\
\hline Physical therapy consultation date & If yes, date ordered? & MM/DD/year & Date \\
\hline Occupational therapy consult & $\begin{array}{l}\text { Did the patient have an occupational therapy consulta- } \\
\text { tion in the hospital? }\end{array}$ & Yes/no/unknown & Binary \\
\hline Occupational therapy consultation date & If yes, date ordered? & MM/DD/year & Date \\
\hline Speech and language therapy consult & $\begin{array}{l}\text { Did the patient have a speech and language therapy } \\
\text { consultation in the hospital? }\end{array}$ & Yes/no/unknown & Binary \\
\hline Speech and language therapy consultation date & If yes, date ordered? & MM/DD/year & Date \\
\hline Rehabilitation consult & $\begin{array}{l}\text { Did the patient have a rehabilitation consultation in the } \\
\text { hospital? }\end{array}$ & Yes/no/unknown & Binary \\
\hline Rehabilitation consultation date & If yes, date ordered? & MM/DD/year & Date \\
\hline
\end{tabular}

compared with 316.9 per 100,000 adults $>65$ years of age [26]. The lower patient volume in the pediatric population makes collecting more detailed data elements possible for the pediatric CRF. Conversely, the low volume expected per country demands multicenter collaboration to attain a large enough sample size to produce robust results to inform clinical care and research initiatives. Some data elements, such as those specific to intensive care admission (e.g., mechanical ventilation, risk of mortality scores), are already standardized and commonly collected in pediatric intensive care units (PICUs). However, many of the baseline and COVID-19-related data elements should harmonize with other pediatric COVID19 studies, none of which (to our knowledge) includes detailed neurological manifestations. Finally, unique data elements specific to pediatrics are necessary in order to account for the following: (1) child age and developmental stage [27, 28]; (2) pediatric-specific risk adjustment [29, 30]; (3) baseline hospital characteristics; (4) differences in pediatric versus adult morbidities, symptoms, treatments, and outcomes; (5) inclusion of multisystem inflammatory syndrome related to COVID-19 (MISC) data elements [31], a pediatric-specific manifestation; and (6) child- and family-validated outcome measures.
Similar to the adult study, the pediatric collective is actively working to establish partnerships with centers and networks affected by COVID-19 in high-, middle-, and low-income countries. To facilitate this aim, we engaged with the LARed ("Red Colaborativa Pediatrica Latinoamericana, or Collaborative Pediatric Latin American Network), which in turn reached out to partner networks including CLaNi (Colegio Latinoamericano de Neurointensivismo), AMCI (Asociacion Colombiana de Medicina Critica y Cuidados Intensivos), and SLACIP (Sociedad Latinoamericana de Cuidados Intensivos Pediatricos SM) to recruit sites outside of LARed. At the time of this writing, these efforts have resulted in 22 registered sites spanning from Mexico to Chile and Argentina. We developed Spanish language versions of study documents and CRF (Table 5). Spanish translation was performed by team members (MS, JDR.) and reviewed and edited by global partners in primary Spanish-speaking regions (PV, SG). As in the adult CRF, data elements were reviewed and adjusted for applicability to the local region and medical abbreviations were avoided. 
Table 5 Pediatric CRF Spanish version (formato para reporte de casos)

\begin{tabular}{|c|c|c|c|}
\hline Variable & Descripción & Valores Admitidos & Tipo de variable \\
\hline Identificación del Sitio & Asignado en la pestaña Sitio ID & Fijo & Fijo \\
\hline Identificación del Participante & Autoasignado & Fijo & Fijo \\
\hline ID del Estudio & Autoasignado & Fijo & Fijo \\
\hline Institución/Hospital & $\begin{array}{l}\text { Nombre de la institución/hospital en el cual está } \\
\text { admitido el paciente }\end{array}$ & Texto Libre & Texto Libre \\
\hline Hospital Académico/Universidad & $\begin{array}{l}\text { El hospital está ubicado en un centro académico o está } \\
\text { afiliado a una universidad? }\end{array}$ & Sí/No/Desconocido & Binario \\
\hline Hospital Pediátrico & Es el hospital exclusivamente pediátrico? & Sí/No/Desconocido & Binario \\
\hline Servicio de Cuidado Crítico Neurológico & ¿Su hospital tiene un servicio de atención neurocrítico? & Sí/No/Desconocido & Binario \\
\hline Número Total Camas Pediátricas & $\begin{array}{l}\text { ¿Cuál es el número total de camas pediátricas en su } \\
\text { centro? (sin contar camas de Cuidados Intensivos } \\
\text { Neonatales) }\end{array}$ & $\#$ & Continuo \\
\hline Total de Camas UCI Pediátrica & $\begin{array}{l}\text { ¿Cuál es el número total de camas en la UCl pediátrica en } \\
\text { su centro? }\end{array}$ & Texto libre & Continuo \\
\hline Fecha de Admisión al hospital & Fecha de admisión al hospital & MM/DD/Año & Fecha \\
\hline Fecha de Admisión a la UCl & Fecha ingreso a la $\mathrm{UCl}$ & MM/DD/Año & Fecha \\
\hline Fecha de alta UCl & Fecha de salida/transferencia desde la UCI & MM/DD/Año & Fecha \\
\hline Fecha de Alta Hospitalaria & Fecha de alta del hospital & MM/DD/Año & Fecha \\
\hline Total Días Hospitalización & Días totales de hospitalización & $\#$ & Continuo \\
\hline Ubicación al alta & Disposición del paciente al dar de alta del hospital & Lista & Nominal \\
\hline Sexo & Sexo biológico del paciente & Lista & Nominal \\
\hline Peso, kg & Ingrese el peso en kilogramos & Texto libre & Continuo \\
\hline Altura $(\mathrm{cm})$ & Introducir la talla/estatura en centímetros & Texto libre & Continuo \\
\hline Años & $\begin{array}{l}\text { La edad del paciente al ingreso al hospital (números } \\
\text { enteros para niños de } 1+\text { año y fracciones para } \\
\text { niños }<1 \text { ) }\end{array}$ & $\#$ & Continuo \\
\hline Raza & Raza del paciente & Lista & Nominal \\
\hline Grupo Étnico & Etnicidad auto-reportada del paciente & Lista & Nominal \\
\hline Comorbilidad: Neurológica & ¿El paciente tiene una comorbilidad neurológica? & Sí/No/Desconocido & Binario \\
\hline Comorbilidad: Cardiovascular & ¿El paciente tiene una comorbilidad cardiovascular? & Sí/No/Desconocido & Binario \\
\hline Comorbilidad: Respiratoria & ¿El paciente tiene una comorbilidad pulmonar? & Sí/No/Desconocido & Binario \\
\hline Comorbilidad: renal o urológica & ¿El paciente tiene una comorbilidad renal o urológica? & Sí/No/Desconocido & Binario \\
\hline Comorbilidad: Gastrointestinal & ¿El paciente tiene una comorbilidad gastrointestinal? & Si/No/Desconocido & Binario \\
\hline Comorbilidad Hematológica o Inmunológica & $\begin{array}{l}\text { ¿El paciente tiene una comorbilidad inmunológica o } \\
\text { hematológica? }\end{array}$ & Sí/No/Desconocido & Binario \\
\hline Comorbilidad: Metabólica & ¿El paciente tiene una comorbilidad metabólica? & Sí/No/Desconocido & Binario \\
\hline $\begin{array}{l}\text { Comorbilidad: Enfermedad Congénita o Defecto Gené- } \\
\text { tico }\end{array}$ & $\begin{array}{l}\text { ¿El paciente tiene un defecto congénito o comorbilidad } \\
\text { genética? }\end{array}$ & Sí/No/Desconocido & Binario \\
\hline Comorbilidad: Malignidad & $\begin{array}{l}\text { El paciente tiene tumor u otra malignidad como comor- } \\
\text { bilidad }\end{array}$ & Sí/No/Desconocido & Binario \\
\hline Comorbilidad: Prematurez o Neonatal & ¿El paciente nació prematuro o es un recién nacido? & Sí/No/Desconocido & Binario \\
\hline Comorbilidad: Dependencia Tecnología & $\begin{array}{l}\text { ¿El paciente requiere soporte tecnológico/maquinas para } \\
\text { su cuidado diario? }\end{array}$ & Sí/No/Desconocido & Binario \\
\hline Comorbilidad:Trasplante & ¿El paciente es receptor de trasplante? & Sí/No/Desconocido & Binario \\
\hline Otra Comorbilidad: no neurológica & ¿El paciente tiene otra comorbilidad (no neurológica)? & Sí/No/Desconocido & Binario \\
\hline COVID Diagnóstico Prueba de PCR & positivo en la prueba PCR & Sí/No/Desconocido & Binario \\
\hline Fecha de Prueba de PCR COVID Positiva & Fecha de PCR positivo en la prueba & MM/DD/Año & Fecha \\
\hline Presunción Diagnóstica de Tener COVID & $\begin{array}{l}\text { Paciente es presuntamente (no probado) positivo, debido } \\
\text { a tener contactos cercanos positivos (el paciente bajo } \\
\text { investigación) }\end{array}$ & Sí/No/Desconocido & Binario \\
\hline
\end{tabular}


Table 5 (continued)

\begin{tabular}{|c|c|c|c|}
\hline Variable & Descripción & Valores Admitidos & Tipo de variable \\
\hline Fecha de Presunción Diagnóstica Positiva COVID & $\begin{array}{l}\text { Fecha en la cual el paciente se considera presuntamente } \\
\text { (no probado) positivo debido a los contactos cercanos } \\
\text { positivos }\end{array}$ & MM/DD/Año & Fecha \\
\hline COVID Test Diagnóstico por Anticuerpos & Positivo en la prueba de anticuerpos & Sí/No/Desconocido & Binario \\
\hline Fecha de Test Diagnóstico por Anticuerpos COVID & Fecha de la prueba de anticuerpos positiva & MM/DD/Año & Fecha \\
\hline $\begin{array}{l}\text { Fecha de Inicio de CUALQUIERA de los } \\
\text { Síntomas de COVID }\end{array}$ & $\begin{array}{l}\text { Fecha en la cual el paciente presentó los síntomas por } \\
\text { primera vez. Si no se sabe, por favor, introduzca la fecha } \\
\text { de admisión }\end{array}$ & MM/DD/Año & Fecha \\
\hline Fecha de Inicio de los síntomas Neurológicos & $\begin{array}{l}\text { Fecha en la cual el paciente desarrolló por primera vez los } \\
\text { síntomas neurológicos }\end{array}$ & MM/DD/Año & Fecha \\
\hline Dolor de cabeza & ¿El paciente se quejó de dolor de cabeza? & Sí/No/Desconocido & Binario \\
\hline Fecha de Inicio de Cefalea & Fecha en la cual se observó cefalea por primera vez. & MM/DD/Año & Fecha \\
\hline Tormenta Simpática/Disautonomía & $\begin{array}{l}\text { ¿El paciente presentó síntomas de deterioro simpático o } \\
\text { disautonomia? }\end{array}$ & Sí/No/Desconocido & Binario \\
\hline Fecha de Tormenta Simpática/Disautonomía & Fecha en la cual se observó por primera vez. & MM/DD/Año & Fecha \\
\hline Anosmia & ¿Se quejó el paciente de alteración para oler? & Sí/No/Desconocido & Binario \\
\hline Fecha de Inicio Anosmia & Fecha en la que se observó por primera vez. & MM/DD/Año & Fecha \\
\hline Ageusia & $\begin{array}{l}\text { ¿El paciente se quejó de pérdida del gusto o de tener } \\
\text { alteración del gusto? }\end{array}$ & Sí/No/Desconocido & Binario \\
\hline Fecha de Inicio Ageusia & Fecha en la cual observó por primera vez. & MM/DD/Año & Fecha \\
\hline Alteraciones Visuales & Se quejo el paciente de visión anormal? & Sí/No/Desconocido & Binario \\
\hline Fecha de Inicio de Alteraciones Visuales & Fecha en la cual se observó por primera vez. & MM/DD/Año & Fecha \\
\hline Síncope & ¿El paciente presentó síncope? & Sí/No/Desconocido & Binario \\
\hline Fecha de Síncope & Fecha en la cual se observó por primera vez. & MM/DD/Año & Fecha \\
\hline Ictus/ACVa & ¿El paciente tuvo un ataque cerebrovascular agudo? & Lista & Binario \\
\hline Fecha de inicio Ictus/ACVa & Fecha en la cual se observó por primera vez. & MM/DD/Año & Fecha \\
\hline $\begin{array}{l}\text { Encefalopatía Aguda (alteración del estado mental, } \\
\text { somnolencia o estupor) }\end{array}$ & $\begin{array}{l}\text { ¿Tuvo el paciente alteración del estado mental, somno- } \\
\text { lencia o estupor de nueva aparición? }\end{array}$ & Sí/No/Desconocido & Binario \\
\hline Fecha de Inicio Agudo de Encefalopatía & Fecha en la que se observó por primera vez & MM/DD/Año & Fecha \\
\hline Paro Cardiorespiratorio & ¿El paciente tuvo parada cardio-respiratoria? & Sí/No/Desconocido & Binario \\
\hline Fecha de Paro Cardiorespiratorio & Fecha en la cual se observó por primera vez & MM/DD/Año & Fecha \\
\hline Meningitis/Encefalitis & ¿Tuvo el paciente meningitis o encefalitis? & Sí/No/Desconocido & Binario \\
\hline Fecha Meningitis/Encefalitis & Fecha en la cual se observó por primera vez. & MM/DD/Año & Fecha \\
\hline Coma & $\begin{array}{l}\text { El paciente presentó coma (no debido a medicaciones) } \\
\text { Definición de coma: no despierta a los estímulos } \\
\text { nocivos, no sigue con los ojos ni hace movimientos con } \\
\text { propósito, no hace apertura ocular espontánea. }\end{array}$ & Sí/No/Desconocido & Binario \\
\hline Fecha de Coma & Fecha en la cual se observó por primera vez. & MM/DD/Año & Fecha \\
\hline Convulsiones Clínicas/Estatus epiléptico & $\begin{array}{l}\text { ¿El paciente desarrolló convulsiones clínicas o estatus } \\
\text { epiléptico? }\end{array}$ & Sí/No/Desconocido & Binario \\
\hline $\begin{array}{l}\text { Fecha de Inicio de Convulsiones Clínicas/Estatus epilép- } \\
\text { tico }\end{array}$ & Fecha en la cual se observó por primera vez. & MM/DD/Año & Fecha \\
\hline Pérdida de la sensibilidad & $\begin{array}{l}\text { ¿El paciente desarrollo entumecimiento o alteración } \\
\text { sensitiva? }\end{array}$ & Sí/No/Desconocido & Binario \\
\hline Fecha de Inicio de Pérdida de la Sensibilidad & Fecha en la cual se observó por primera vez. & MM/DD/Año & Fecha \\
\hline Debilidad & ¿El paciente desarrollo debilidad motora? & Sí/No/Desconocido & Binario \\
\hline Fecha de Inicio Debilidad & Fecha en la cual se observó por primera vez. & MM/DD/Año & Fecha \\
\hline Neuropatía & ¿El paciente desarrollo neuropatía? & Sí/No/Desconocido & Binario \\
\hline Fecha de Inicio Neuropatía & Fecha en la cual se observó por primera vez. & MM/DD/Año & Fecha \\
\hline Parestesias & ¿El paciente desarrolló parestesias? & Sí/No/Desconocido & Binario \\
\hline Fecha de Inicio Parestesia & Fecha en la cual se observó por primera vez. & MM/DD/Año & Fecha \\
\hline Mielopatía & ¿El paciente mostró signos de mielopatía? & Sí/No/Desconocido & Binario \\
\hline
\end{tabular}


Table 5 (continued)

\begin{tabular}{|c|c|c|c|}
\hline Variable & Descripción & Valores Admitidos & Tipo de variable \\
\hline Fecha de Inicio Mielopatía & Fecha en la cual se observó por primera vez. & MM/DD/Año & Fecha \\
\hline Mareo & ¿El paciente se quejo de mareos? & Sí/No/Desconocido & Binario \\
\hline Fecha de Inicio Mareo & Fecha en la cual se observó por primera vez. & MM/DD/Año & Fecha \\
\hline Ataxia & ¿El paciente mostró signos de ataxia? & Sí/No/Desconocido & Binario \\
\hline Fecha de Inicio Ataxia & Fecha en la cual se observó por primera vez. & MM/DD/Año & Fecha \\
\hline Otras manifestaciones neurológicas & $\begin{array}{l}\text { Si el paciente presentó otras manifestaciones neurológi- } \\
\text { cas, por favor describirlas }\end{array}$ & Texto Libre & Binario \\
\hline Fecha de inicio de Otras Manifestaciones Neurológicas & Fecha en la cual se observó por primera vez. & MM/DD/Año & Fecha \\
\hline Fiebre & ¿Tuvo fiebre? & Sí/No/Desconocido & Binario \\
\hline Fecha de Inicio Fiebre & Fecha en la cual se observó por primera vez. & MM/DD/Año & Fecha \\
\hline Tos & ¿El paciente tuvo tos? & Sí/No/Desconocido & Binario \\
\hline Fecha de Inicio de la Tos & Fecha en la cual se observó por primera vez. & MM/DD/Año & Fecha \\
\hline Delirio & $\begin{array}{l}\text { ¿El paciente tuvo delirio? (definido como alteración del } \\
\text { contenido de conciencia, lenguaje o comportamiento } \\
\text { confuso o incoherente) }\end{array}$ & Sí/No/Desconocido & Binario \\
\hline Fecha de Inicio Delirio & Fecha en la cual se observó por primera vez. & MM/DD/Año & Fecha \\
\hline ¿Cómo se Diagnosticó el Delirio? & $\begin{array}{l}\text { Método de puntaje o herramienta para definir delirio } \\
\text { (describir o nombrar) }\end{array}$ & Texto libre & Texto libre \\
\hline Anorexia & ¿El paciente tuvo anorexia? & Sí/No/Desconocido & Binario \\
\hline Fecha de Inicio de la Anorexia & Fecha en la cual se observó por primera vez. & MM/DD/Año & Fecha \\
\hline Diarrea & El paciente tuvo diarrea? & Sí/No/Desconocido & Binario \\
\hline Fecha de Aparición de la Diarrea & Fecha en la cual se observó por primera vez. & MM/DD/Año & Fecha \\
\hline Dolor de Garganta & ¿El paciente tuvo dolor de garganta? & Sí/No/Desconocido & Binario \\
\hline Fecha de Inicio del Dolor de Garganta & Fecha en la cual se observó por primera vez. & MM/DD/Año & Fecha \\
\hline Dolor Abdominal & ¿El paciente tuvo dolor abdominal? & Sí/No/Desconocido & Binario \\
\hline Fecha de inicio del dolor abdominal & Fecha en la cual se observó por primera vez. & MM/DD/Año & Fecha \\
\hline EEG & ¿Se realizó un EEG? & Sí/No/Desconocido & Binario \\
\hline Fecha EEG & Fecha del primer EEG & MM/DD/Año & Fecha \\
\hline Resultados de EEG & Los resultados del EEG & Lista & Binario \\
\hline Lectura Final EEG & Lectura final del primer EEG & Texto libre & Texto libre \\
\hline Tomografía Cerebral & ¿Se realizó un TAC de cerebro? & Sí/No/Desconocido & Binario \\
\hline Fecha de Tomografía Cerebral & Fecha de la primera TAC de cerebro & MM/DD/Año & Fecha \\
\hline Resultados Tomografía cerebral & Los resultados del primer TAC cerebral & Lista & Binario \\
\hline Lectura Final Tomografía cerebral & lectura final del primer TAC cerebral & Texto libre & Texto libre \\
\hline RM cerebral & ¿Se realizo una resonancia magnética del cerebro? & Sí/No/Desconocido & Binario \\
\hline Fecha RM Cerebral & Fecha de la primera resonancia magnética del cerebro & MM/DD/Año & Fecha \\
\hline Resultados RM Cerebral & $\begin{array}{l}\text { Resultados de la primera resonancia magnética del } \\
\text { cerebro }\end{array}$ & Lista & Binario \\
\hline Lectura final RM Cerebral & $\begin{array}{l}\text { lectura final de la primera resonancia magnética del } \\
\text { cerebro }\end{array}$ & Texto libre & Texto libre \\
\hline Prueba LCR (líquido cefalorequideo) & ¿Se analizó LCR? & Sí/No/Desconocido & Binario \\
\hline Fecha del Primer Análisis de LCR & Fecha de estudios de primer LCR & MM/DD/Año & Fecha \\
\hline Recuento Celular WBC en LCR & $\begin{array}{l}\text { Recuento glóbulos blancos WBC en líquido cefalor- } \\
\text { raquídeo }\end{array}$ & $\#$ & Continuo \\
\hline Recuento de Células RBC en LCR & Recuento glóbulos rojos en líquido cefalorraquídeo & \# & Continuo \\
\hline Glucosa LCR & Glucosa mg/dl en líquido cefalorraquídeo & $\#$ & Continuo \\
\hline Proteína LCR & Proteína mg/dl en líquido cefalorraquídeo & $\#$ & Continuo \\
\hline Cultivo de LCR (viral y/o bacteriana) & Resultados del cultivo LCR & Texto libre & Texto libre \\
\hline PCR en LCR & Resultados PCR & Texto libre & Texto libre \\
\hline Prueba COVID en LCR & Prueba COVID PCR en líquido cefalorraquídeo & Lista & Binario \\
\hline
\end{tabular}


Table 5 (continued)

\begin{tabular}{|c|c|c|c|}
\hline Variable & Descripción & Valores Admitidos & Tipo de variable \\
\hline Presión Apertura & Presión de apertura LCR en cm H2O & \# & Continuo \\
\hline LCR Otros Resultados & $\begin{array}{l}\text { anticuerpos, bandas oligoclonales, moléculas inflamato- } \\
\text { rias tales como IL-6, etc. }\end{array}$ & Texto libre & Texto libre \\
\hline ECMO & $\begin{array}{l}\text { ¿El paciente requirió terapia de oxigenación por mem- } \\
\text { brana extracorpórea durante la hospitalización? }\end{array}$ & Sí/No/Desconocido & Binario \\
\hline Días de ECMO & ¿Cuántos días estuvo el paciente en ECMO? & \# & Continuo \\
\hline ECPR & $\begin{array}{l}\text { ¿El paciente fue colocado en ECMO durante reanimación } \\
\text { activa? }\end{array}$ & Sí/No/Desconocido & Binario \\
\hline Fecha ECPR & Fecha en la cual se observó por primera vez. & MM/DD/Año & Fecha \\
\hline Diálisis/TRRC & $\begin{array}{l}\text { ¿El paciente desarrolló lesión aguda renal que necesitó } \\
\text { terapia de diálisis/reemplazo continuo renal (TRRC)? }\end{array}$ & Sí/No/Desconocido & Binario \\
\hline Días de Diálisis/TRRC & ¿Cuántos días estuvo el paciente en diálisis/TRRC? & \# & Continuo \\
\hline Ventilación Mecánica Invasiva & $\begin{array}{l}\text { ¿El paciente necesito intubación y ventilación mecánica } \\
\text { durante la estadía en cuidados críticos? }\end{array}$ & Sí/No/Desconocido & Binario \\
\hline Días de Ventilación Mecánica Invasiva & $\begin{array}{l}\text { ¿Cuántos días recibió el paciente ventilación mecánica } \\
\text { invasiva? }\end{array}$ & \# & Continuo \\
\hline Ventilación Mecánica No invasiva & $\begin{array}{l}\text { ¿El paciente necesitó ventilación mecánica no- invasiva } \\
\text { durante la estadía en cuidados críticos? }\end{array}$ & Sí/No/Desconocido & Binario \\
\hline Días de Ventilación Mecánica No Invasiva & $\begin{array}{l}\text { ¿Cuántos días estuvo el paciente en ventilación mecánica } \\
\text { no invasiva? }\end{array}$ & $\#$ & Continuo \\
\hline Monitor de PIC (Presión Intracraneal) & ¿El paciente tuvo un monitor de presión intracraneal? & Sí/No/Desconocido & Binario \\
\hline Tipo de dispositivo de PIC & ¿Qué tipo de monitor de PIC fue colocado? & Lista & Binario \\
\hline Fecha Colocación Monitor PIC & Fecha en la cual se colocó el monitor de PIC & MM/DD/Año & Fecha \\
\hline Total Días Monitoreo PIC & En caso afirmativo, ¿cuántos días tuvo el monitor PIC? & $\#$ & Continuo \\
\hline PIC inicial & Presión intracraneal inicial, mmHg & \# & Continuo \\
\hline Pico Máximo de PIC & $\begin{array}{l}\text { Pico de la presión intracraneal (PIC valores de registro que } \\
\text { se mantuvieron }>2 \text { min) }\end{array}$ & \# & Continuo \\
\hline Fecha Pico Máximo de PIC & Día del pico de la PIC & MM/DD/Año & Fecha \\
\hline Presión de Perfusión Cerebral más Baja & $\begin{array}{l}\text { Valor más bajo de la presión de perfusión cerebral PPC } \\
\text { (Presión arterial media -PIC) }\end{array}$ & $\#$ & Continuo \\
\hline Día de Presión de Perfusión Cerebral más Baja & Día del PPC más bajo & MM/DD/Año & Fecha \\
\hline Causa de la Muerte & $\begin{array}{l}\text { ¿Cuál fue la causa de la muerte en el hospital si el } \\
\text { paciente murió? }\end{array}$ & Texto libre & Texto libre \\
\hline Índice de Mortalidad Pediátrica (PIM) & $\begin{array}{l}\text { La puntuación PIM en ingreso hospitalario (véase "guías } \\
\text { de puntuación" ficha de tanteo) }\end{array}$ & $\# \%$ & Continuo \\
\hline Glasgow Coma Score (GCS) & $\begin{array}{l}\text { Puntuación de GCS al ingreso del hospital (si no hay } \\
\text { bloqueo neuromuscular) }\end{array}$ & $3-15$ & Ordinal \\
\hline Pediatric Logistic Organ Disfunction-2 (PELOD) & $\begin{array}{l}\text { Puntuación de PELOD en la admisión hospitalaria (Ver } \\
\text { "guías de puntuación" ficha de anexa }\end{array}$ & \# & Continuo \\
\hline WBC & Introducir glóbulos blancos con dos decimales & \# & Continuo \\
\hline Linfocitos & Introducir linfocitos absolutos en la admisión & \# & Continuo \\
\hline Linfocitos más Bajos & $\begin{array}{l}\text { introducir recuento absoluto de linfocitos más bajo } \\
\text { durante la hospitalización }\end{array}$ & \# & Continuo \\
\hline Fecha de Linfocitos más Bajos & Fecha de valor de laboratorio & MM/DD/Año & Fecha \\
\hline Plaquetas & Introducir recuento de plaquetas en la admisión & \# & Continuo \\
\hline Plaqueta más Bajas & $\begin{array}{l}\text { Introducir el recuento de plaquetas más bajo durante la } \\
\text { hospitalización }\end{array}$ & $\#$ & Continuo \\
\hline Fecha Plaqueta más Bajas & Fecha de valor de laboratorio & MM/DD/Año & Fecha \\
\hline Sodio & Nivel de sodio en sangre mmol/L en la admisión & \# & Continuo \\
\hline Hemoglobina & Introducir el nivel de hemoglobina g/dl en la admisión & \# & Continuo \\
\hline IL-6 (primera) & Introducir valor de IL-6 si se hace & \# & Continuo \\
\hline Fecha IL-6 (primera) & Fecha de valor de laboratorio & MM/DD/Año & Fecha \\
\hline PCR (Proteína C Reactiva) & Introducir primera PCR mg/dl & $\#$ & Continuo \\
\hline PCR más Alta & Introducir el valor más alto de la PCR durante admisión & \# & Continuo \\
\hline
\end{tabular}


Table 5 (continued)

\begin{tabular}{|c|c|c|c|}
\hline Variable & Descripción & Valores Admitidos & Tipo de variable \\
\hline Fecha de PCR más alta & Fecha de valor de laboratorio & MM/DD/Año & Fecha \\
\hline Ferritina & Introducir primera ferritina ng/ml & $\#$ & Continuo \\
\hline Ferritina más Alta & $\begin{array}{l}\text { Introducir el valor más alto de ferritina durante la hospi- } \\
\text { talización }\end{array}$ & \# & Continuo \\
\hline Fecha de Ferritina más Alta & Fecha de valor de laboratorio & MM/DD/Año & Fecha \\
\hline Procalcitonina & Introducir valor de la procalcitonina, ng/mL & $\#$ & Continuo \\
\hline Procalcitonina más alta & $\begin{array}{l}\text { Introducir el valor más alto de la procalcitonina ng/ml } \\
\text { durante la hospitalización }\end{array}$ & \# & Continuo \\
\hline Fecha de Procalcitonina más Alta & Fecha de valor de laboratorio & MM/DD/Año & Fecha \\
\hline Fibrinógeno & Fibrinógeno al ingreso, mg/dl & $\#$ & Continuo \\
\hline Fibrinógeno más Bajo & $\begin{array}{l}\text { introducir fibrinógeno más bajo durante la hospitali- } \\
\text { zación, mg/dl }\end{array}$ & $\#$ & Continuo \\
\hline Fecha Fibrinógeno más Bajo & Fecha de valor de laboratorio & MM/DD/Año & Fecha \\
\hline ALT & Introducir primer ALT, Intl U/L & \# & Continuo \\
\hline ALT más Alto & $\begin{array}{l}\text { Introducir el valor más alto de ALT durante la hospitali- } \\
\text { zación, Intl U/I }\end{array}$ & \# & Continuo \\
\hline Fecha de ALT más Alto & Fecha de valor de laboratorio & MM/DD/Año & Fecha \\
\hline AST & Introducir primer AST & $\#$ & Continuo \\
\hline AST más Alto & $\begin{array}{l}\text { Introducir el valor más alto de AST durante la hospitali- } \\
\text { zación }\end{array}$ & \# & Continuo \\
\hline Fecha de AST más Alto & Fecha de valor de laboratorio & MM/DD/Año & Fecha \\
\hline TP & introducir el primer tiempo de protrombina (TP) & $\#$ & Continuo \\
\hline TP más Aalto & $\begin{array}{l}\text { introducir el valor más alto de TP durante la hospitali- } \\
\text { zación }\end{array}$ & \# & Continuo \\
\hline Fecha de TP más Alto & Fecha de valor de laboratorio & MM/DD/Año & Fecha \\
\hline TPT & $\begin{array}{l}\text { Introducir el primer TPT (tiempo de tromboplastina } \\
\text { parcial) }\end{array}$ & \# & Continuo \\
\hline TPT más Alto & $\begin{array}{l}\text { introducir el valor más alto de TPT durante la hospitali- } \\
\text { zación }\end{array}$ & \# & Continuo \\
\hline Fecha de TPT más Alto & Fecha de valor de laboratorio & MM/DD/Año & Fecha \\
\hline INR & Introducir primero INR (índice normalizado) & $\#$ & Continuo \\
\hline INR más Alto & introducir más alto INR durante la hospitalización & $\#$ & Continuo \\
\hline Fecha de INR más alto & Fecha de valor de laboratorio & MM/DD/Año & Fecha \\
\hline Dímero-D & Introducir primer valor del D-dímero & \# & Continuo \\
\hline Dímero-D más Alto & introducir valor más alto del dímero D la hospitalización & \# & Continuo \\
\hline Fecha de Dímero-D más Alto & Fecha de valor de laboratorio & MM/DD/Año & Fecha \\
\hline Cultivo de Sangre Positivo & Tuvo el paciente un hemocultivo positivo? & Sí/No/Desconocido & Binario \\
\hline Fecha de Hemocultivo & Fecha de envío de cultivo de sangre & MM/DD/Año & Fecha \\
\hline Resultados hemocultivo & Resultados de cultivo de sangre positivo & Texto libre & Texto libre \\
\hline Cultivo Respiratorio Positivo & Tuvo el paciente un cultivo respiratorio positivo & Sí/No/Desconocido & Binario \\
\hline Fecha de Cultivo Respiratorio & Fecha de envío cultivo respiratorio & MM/DD/Año & Fecha \\
\hline Resultados Cultivo Respiratorio & resultados del cultivo respiratoria positivo & Texto libre & Texto libre \\
\hline Panel Viral Respiratorio (no COVID-19)? & ¿Se hizo panel de virus respiratorio (no para COVID-19)? & Sí/No/Desconocido & Binario \\
\hline Fecha Panel Viral respiratorio & Fecha envió del panel respiratorio viral si se hizo & MM/DD/Año & Fecha \\
\hline Resultados del panel Viral Respiratorio & Resultados de panel de respiratorio viral & Texto libre & Texto libre \\
\hline Otras Coinfecciones Detectadas? & Lista de otras coinfecciones (organismos, lugares, fechas) & Texto libre & Texto libre \\
\hline Peor pH Gases Sanguíneos (intubado) & $\begin{array}{l}\text { Introducir valor mas bajo de } \mathrm{pH} \text { en gases arteriales mien- } \\
\text { tras estaba intubado }\end{array}$ & $\#$ & Continuo \\
\hline Fecha de pH más bajo de Gases Sanguíneos (intubado) & Fecha de valor de laboratorio & MM/DD/Año & Fecha \\
\hline pO2 más bajo en Gases Sanguíneos (intubado) & $\begin{array}{l}\text { Introduce bajo ABG pO2, mientras que si se hace } \\
\text { intubado }\end{array}$ & $\#$ & Continuo \\
\hline Fecha de pO2 más bajo en Gases Sanguíneos (intubado) & Fecha de valor de laboratorio & MM/DD/Año & Fecha \\
\hline
\end{tabular}


Table 5 (continued)

\begin{tabular}{|c|c|c|c|}
\hline Variable & Descripción & Valores Admitidos & Tipo de variable \\
\hline Índice de oxigenación (IO) más alto (intubado) & $\begin{array}{l}\text { introducir } \mathrm{IO} \text { asociado con peor pO2 mientras intubado si } \\
\text { se hicieron gases arteriales (https://www.mdcalc.com/ } \\
\text { oxygenation-index) }\end{array}$ & \# & Continuo \\
\hline Fecha de Índice de Oxigenación (IO más alto) (intubado) & Fecha de valor de laboratorio & MM/DD/Año & Fecha \\
\hline PCO2 mas Alto en Gases Sanguíneos (intubado) & $\begin{array}{l}\text { Introducir el valor más alto de pCO2, mientras intubado, } \\
\text { en gases arteriales }\end{array}$ & $\#$ & Continuo \\
\hline Fecha de PCO2 mas Alto & Fecha de valor de laboratorio & MM/DD/Año & Fecha \\
\hline Tratamiento Empírico COVID-19 \# 1 & $\begin{array}{l}\text { Introducir medicación utilizada para el tratamiento } \\
\text { empírico COVID-19 }\end{array}$ & Texto libre & Texto libre \\
\hline Si Eligió "otro," Describir & Enumerar otros tratamientos empíricos para COVID-19 & Texto libre & Texto libre \\
\hline Fecha de Tratamiento Empírico COVID-19 \# 1 & Fecha inicio tratamiento empírico COVID \# 1 & MM/DD/Año & Fecha \\
\hline Dosificación y Duración del Tratamiento COVID-19 \# 1 & $\begin{array}{l}\text { introducir la dosificación para cualquier medicamento \# } 1 \\
\text { utilizada para empírico tratamiento COVID-19 }\end{array}$ & Texto libre & Texto libre \\
\hline Tratamiento Empírico COVID-19 \# 2 & $\begin{array}{l}\text { introducir segundo medicamento que se utiliza para el } \\
\text { tratamiento empírico covid-19 }\end{array}$ & Texto libre & Texto libre \\
\hline Si Elligió "otro," Mencione & enumerar otros empíricos Covic 19 tratamientos & Texto libre & Texto libre \\
\hline Fecha de Tratamiento Empírico COVID-19 \# 2 & Fecha inicio de tratamiento empírico COVID \# 2 & MM/DD/Año & Fecha \\
\hline Dosificación y Duración del Tratamiento COVID-19 \# 2 & $\begin{array}{l}\text { Introducir la dosificación para cualquier medicamento \# } 2 \\
\text { utilizado para tratamiento empírico COVID-19 }\end{array}$ & Texto libre & Texto libre \\
\hline Tratamiento Empírico COVID-19 \# 3 & $\begin{array}{l}\text { Introducir tercera medicación utilizada para el tratami- } \\
\text { ento empírico COVID-19 }\end{array}$ & Texto libre & Texto libre \\
\hline Si eligió "otro," Mencione & Enumerar otros tratamientos empíricos COVID-19 & Texto libre & Texto libre \\
\hline Fecha de Tratamiento Empírico COVID-19 \# 3 & Fecha Inicio tratamiento empírico COVID \# 3 & MM/DD/Año & Fecha \\
\hline La Dosificación y duración del Tratamiento COVID-19 \# 3 & $\begin{array}{l}\text { Introducir la dosificación para cualquier medicamento \# } 3 \\
\text { utilizado para tratamiento empírico COVID-19 }\end{array}$ & Texto libre & Texto libre \\
\hline Tratamiento Empírico COVID-19 \# 4 & $\begin{array}{l}\text { Introducir cuarta medicación utilizada para el tratamiento } \\
\text { empírico COVID-19 }\end{array}$ & Texto libre & Texto libre \\
\hline Si eligió "otro," mencione & Enumerar otros tratamientos empíricos COVID-19 & Texto libre & Texto libre \\
\hline Fecha de Tratamiento Empírico COVID-19 \# 4 & Fecha de inicio tratamiento empírico \#4 & MM/DD/Año & Fecha \\
\hline La Dosificación y Duración del Tratamiento COVID-19 \# 4 & $\begin{array}{l}\text { Introducir la dosificación para cualquier medicamento \# } 4 \\
\text { utilizado para tratamiento empírico COVID-19 }\end{array}$ & Texto libre & Texto libre \\
\hline Tratamiento Empírico COVID-19 \# 5 & $\begin{array}{l}\text { Introducir quinta medicación utilizada para tratamiento } \\
\text { empírico COVID-19 }\end{array}$ & Texto libre & Texto libre \\
\hline Si eligió "otro," Mencione & Fecha de inicio tratamiento empírico \# 5 & MM/DD/Año & Fecha \\
\hline Fecha de Tratamiento Empírico COVID-19 \# 5 & $\begin{array}{l}\text { Introducir la dosificación para cualquier medicamento \# } 5 \\
\text { usado para tratamiento empírico COVID-19 }\end{array}$ & Texto libre & Texto libre \\
\hline Dosificación y Duración del Tratamiento COVID-19 \# 5 & $\begin{array}{l}\text { Introducir la dosificación para cualquier medicamento \# } 5 \\
\text { usado para tratamiento empírico COVID-19 }\end{array}$ & Texto libre & Texto libre \\
\hline $\begin{array}{l}\text { Síndrome inflamatorio Multisistémico relacionado con } \\
\text { COVID-19 }\end{array}$ & El paciente tuvo este síndrome diagnosticado? & Sí/No/Desconocido & Binario \\
\hline $\begin{array}{l}\text { Fecha de Síndrome inflamatorio Multisistémico relacio- } \\
\text { nado con COVID-19 }\end{array}$ & Fecha en la cual se observó por primera vez. & MM/DD/Año & Fecha \\
\hline Tratamiento Empírico MIS-C \# 1 & $\begin{array}{l}\text { Introducir primera terapia que se usó para el tratamiento } \\
\text { empírico Síndrome }\end{array}$ & Texto libre & Texto libre \\
\hline Fecha de Tratamiento Empírico MIS-C \# 1 & $\begin{array}{l}\text { Introducir primera terapia que se usó para el tratamiento } \\
\text { empírico fecha de inicio Síndrome }\end{array}$ & MM/DD/Año & Fecha \\
\hline $\begin{array}{l}\text { Dosificación y duración del Tratamiento Empírico MIS-C } \\
\text { \# } 1\end{array}$ & $\begin{array}{l}\text { Entrar dosificación para cualquier medicamento \# } 1 \text { se } \\
\text { usa para el tratamiento empírico del Síndrome }\end{array}$ & Texto libre & Texto libre \\
\hline Tratamiento Empírico MIS-C \# 2 & $\begin{array}{l}\text { Introducir segundo medicamento que se utilizó para el } \\
\text { tratamiento empírico Síndrome }\end{array}$ & Texto libre & Texto libre \\
\hline Fecha del Tratamiento Empírico MIS-C \# 2 & $\begin{array}{l}\text { Introducir segunda terapia si se usó para el tratamiento } \\
\text { empírico del Síndrome }\end{array}$ & MM/DD/Año & Fecha \\
\hline $\begin{array}{l}\text { Dosificación y duración del Tratamiento Empírico MIS-C } \\
\text { \#2 }\end{array}$ & $\begin{array}{l}\text { Entrar en la dosificación para cualquier medicamento \# } 2 \\
\text { se utilizó para el tratamiento empírico del Síndrome }\end{array}$ & Texto libre & Texto libre \\
\hline Tratamiento Empírico MIS-C \# 3 & $\begin{array}{l}\text { Introducir tercera medicamento que se utiliza para el } \\
\text { tratamiento empírico del Síndrome }\end{array}$ & Texto libre & Texto libre \\
\hline
\end{tabular}


Table 5 (continued)

\begin{tabular}{|c|c|c|c|}
\hline Variable & Descripción & Valores Admitidos & Tipo de variable \\
\hline Fecha del Tratamiento Empírico MIS-C \# 3 & $\begin{array}{l}\text { Introducir tercera terapia que se utilizó para el tratami- } \\
\text { ento empírico fecha de inicio Síndrome }\end{array}$ & MM/DD/Año & Fecha \\
\hline $\begin{array}{l}\text { Dosificación y duración del Tratamiento Empírico MIS-C } \\
\text { \#3 }\end{array}$ & $\begin{array}{l}\text { Entrar dosificación para cualquier medicamento \# } 3 \text { en el } \\
\text { manejo empírico del Síndrome }\end{array}$ & Texto libre & Texto libre \\
\hline Tratamiento Empírico MIS-C \# 4 & $\begin{array}{l}\text { Introducir cuarto medicamento que se utilizó para el } \\
\text { tratamiento empírico del Síndrome }\end{array}$ & Texto libre & Texto libre \\
\hline Fecha del Tratamiento Empírico MIS-C \# 4 & $\begin{array}{l}\text { Introducir cuarto terapia para el tratamiento empírico } \\
\text { fecha de inicio Síndrome }\end{array}$ & MM/DD/Año & Fecha \\
\hline $\begin{array}{l}\text { Dosificación y duración del Tratamiento Empírico MIS-C } \\
\text { \# }\end{array}$ & $\begin{array}{l}\text { Entrar dosificación para cualquier medicamento \# } 4 \text { para } \\
\text { el tratamiento empírico del Síndrome }\end{array}$ & Texto libre & Texto libre \\
\hline Tratamiento Empírico MIS-C \# 5 & $\begin{array}{l}\text { Introducir quinto medicamento que se utiliza para el } \\
\text { tratamiento empírico Síndrome }\end{array}$ & Texto libre & Texto libre \\
\hline Fecha del Tratamiento Empírico MIS-C \# 5 & $\begin{array}{l}\text { Introducir quinto terapia que se usa para el tratamiento } \\
\text { empírico fecha de inicio Síndrome }\end{array}$ & MM/DD/Año & Fecha \\
\hline $\begin{array}{l}\text { Dosificación y duración del Tratamiento Empírico MIS-C } \\
\text { \# } 5\end{array}$ & $\begin{array}{l}\text { Entrar dosificación para cualquier medicamento \# } 5 \\
\text { usado para el tratamiento empírico del Síndrome }\end{array}$ & Texto libre & Texto libre \\
\hline PCPC Puntaje Inicial (Pre-admisión) & $\begin{array}{l}\text { Entrar puntaje de base en la Categoría Pediátrica de } \\
\text { Rendimiento Cerebral (asignar a posteriori) (véase "guías de } \\
\text { puntuación" para obtener información de puntuación) }\end{array}$ & $\#$ & Ordinal \\
\hline PCPC al Momento de Admisión al Hospital & $\begin{array}{l}\text { Entrar el puntaje en la admisión de la categoría de } \\
\text { rendimiento cerebral pediátrica (véase "guías de pun- } \\
\text { tuación" para obtener información de puntuación) }\end{array}$ & \# & Ordinal \\
\hline PCPC al Alta Hospitalaria & $\begin{array}{l}\text { Introducir la puntuación al alta de la categoría pediátrica } \\
\text { de Rendimiento Cerebral (véase "guías de puntuación" } \\
\text { para obtener información de puntuación) }\end{array}$ & $\#$ & Ordinal \\
\hline Puntaje Inicial FSS (pre-admisión) & $\begin{array}{l}\text { Introducir puntaje en la escala estado funcional basal } \\
\text { (véase "guías de puntuación" para obtener información } \\
\text { de puntuación) }\end{array}$ & $\#$ & Ordinal \\
\hline FSS de Admisión al Hospital & $\begin{array}{l}\text { Introducir la escala del estado funcional del ingreso (Ver } \\
\text { "guías de puntuación" para obtener información de } \\
\text { puntuación) }\end{array}$ & $\#$ & Ordinal \\
\hline FSS al Alta Hospitalaria & $\begin{array}{l}\text { Introducir la escala del estado funcional de egreso (véase } \\
\text { "guías de puntuación" para obtener información de } \\
\text { puntuación) }\end{array}$ & \# & Ordinal \\
\hline Consulta de Terapia Física & ¿El paciente tuvo consulta de fisioterapia en el hospital? & Sí/No/Desconocido & Binario \\
\hline Fecha de Consulta de Terapia física & En caso afirmativo, ¿la fecha ordenados? & MM/DD/Año & Fecha \\
\hline Consulta de Terapia Ocupacional & $\begin{array}{l}\text { ¿El paciente tuvo una consulta de terapia ocupacional en } \\
\text { el hospital? }\end{array}$ & Sí/No/Desconocido & Binario \\
\hline Fecha de Consulta de Terapia Ocupacional & En caso afirmativo, ¿la fecha en la cual fue ordenada? & MM/DD/Año & Fecha \\
\hline Consulta de Terapia del lenguaje (fonoaudiología) & ¿El paciente tuvo consulta de fonoaudiología en el hospital? & Sí/No/Desconocido & Binario \\
\hline Fecha de Consulta de Terapia del lenguaje (Fonoaudiología) & En caso afirmativo, ¿la fecha en la cual fue ordenada? & MM/DD/Año & Fecha \\
\hline Consulta de Rehabilitación & $\begin{array}{l}\text { ¿El paciente tiene una consulta de rehabilitación en el } \\
\text { hospital? }\end{array}$ & Sí/No/Desconocido & Binario \\
\hline Fecha de Consulta de Rehabilitación & ¿En caso afirmativo, la fecha ordenados? & MM/DD/Año & Fecha \\
\hline
\end{tabular}

\section{Conclusion}

We report the general guiding principles and framework for the development of CRFs for a global consortium during a global pandemic crisis. Unique features and considerations include: (1) timeline and speed-in order to address an explosive pandemic, we had to adopt an extremely accelerated and succinct process for CRF development, consensus CDE development, and data harmonization; (2) pragmatism and feasibility in a pandemic-the CRF and data elements present minimal burden to frontline clinicians who populate these data, including minimizing exposure risk and PPE use; (3) adaptation to rapid change-new data and information rapidly emerge in this new pandemic and studies must run on an accelerated timeline to provide timely and accurate information to the public; (4) inclusion of the life span to understand age-related effects; and (5) global partnerships and adaptation of CRF into multiple languages. As a result of this initiative, to date, there are 218 registered sites for the study representing 109 countries 
spanning six continents across the globe, and formal collaborations with other large research networks such as the European Academy of Neurology (EAN) NeuroCOVID Registry (ENERGY) [32] have been established. Participation on working groups within the World Health Organization is ongoing to align efforts with other initiatives related to neurological implications of COVID-19 $[18,33]$. Throughout this work, the adaptable, layered design of the GCS-NeuroCOVID consortium affords a nimble yet systematic and scientific approach that may ultimately serve as a model for future studies that require rapid execution in the midst of pandemics or other overwhelming natural disasters.

\begin{abstract}
Author details
${ }^{1}$ College of Nursing, The Ohio State University, Columbus, OH, USA. ${ }^{2}$ Division of Pediatric Critical Care Medicine and Safar Center for Resuscitation Research, UPMC Children's Hospital of Pittsburgh, Pittsburgh, PA, USA. ${ }^{3}$ Primary Children's Hospital, University of Utah School of Medicine, Salt Lake City, UT, USA. ${ }^{4}$ Division of Stroke and Neurocritical Care, Department of Neurology, The Ohio State University, Columbus, OH, USA. ${ }^{5}$ Neurocritical Care Unit, Department of Neurology, Medical University of Innsbruck, Innsbruck, Austria. ${ }^{6}$ Departments of Anesthesiology and Critical Care Medicine, and Pediatrics, The Johns Hopkins University SOM, Johns Hopkins Children's Center, Baltimore, MD, USA. ${ }^{7}$ Department of Neuro-Intensive Care and Anesthesiology, Fundacio Valle del Lili, University Hospital, Cali, Colombia. ${ }^{8}$ Paulo Niemeyer State Brain Institute, Rio de Janeiro, Brazil. ${ }^{9}$ National Institute of Infectious Diseases Evandro Chagas, Fundação Oswaldo Cruz (FIOCRUZ), Rio de Janeiro, Brazil. ${ }^{10}$ Department of Pediatric Neurology and Critical Care, Universidad Nacional de Colombia and Fundación Universitaria de Ciencias de la Salud, Bogotá, Colombia. ${ }^{11}$ The University of Pittsburgh Medical Center, Pittsburgh, PA, USA. ${ }^{12}$ Department of Neurology, NYU Grossman School of Medicine, New York, NY, USA. ${ }^{13}$ Department of Neurology, Universidad San Francisco de Quito (USFQ), de los Valles Quito, Ecuador. ${ }^{14}$ Division of Anaesthesia, University of Cambridge, Addenbrooke's Hospital Cambridge, Cambridge, UK. ${ }^{15}$ Departments of Anesthesiology and Critical Care Medicine, Neurology, and Neurosurgery, The Johns Hopkins University School of Medicine, Baltimore, MD, USA. ${ }^{16}$ Departments of Critical Care Medicine, Neurology, and Neurosurgery, University of Pittsburgh School of Medicine, Safar Center for Resuscitation Research, Pittsburgh, PA, USA.
\end{abstract}

\section{Acknowledgements}

GCS-NeuroCOVID Consortium Steering Committee Members: Paul Vespa MD, Javier Provencio MD PhD, Daiwai Olson RN PhD, Claude Hemphill MD, Jose Suarez MD, Chethan Rao MD, and Nerissa Ko MD MS. Pediatric Consortium Coordinators: Pamela Rubin, RN and David Maloney, BS. Department of Critical Care Medicine, UPMC Children's Hospital of Pittsburgh, Pittsburgh, USA. Pediatric Consortium Neurointensivists: Dennis Simon, MD, Department of Critical Care Medicine, UPMC Children's Hospital of Pittsburgh, Pittsburgh, PA, USA; Elizabeth Wells, MD, MHS, Division of Neurology, Children's National Hospital, Washington, D.C., USA; Juan Piantino, MD, Division of Neurology, Oregon Health \& Science University; Andrew Geneslaw, MD, Department of Pediatrics, Morgan Stanley Children's Hospital; Alexis A. Topjian, MD, MSc, Division of Pediatric Critical Care Medicine, Children's Hospital of Philadelphia; Jose A. Pineda, MD, Division of Pediatric Critical Care Medicine, Children's Hospital of Los Angeles; and Kristen P. Guilliams, MD, Division of Pediatric Critical Care Medicine, St. Louis Children's Hospital. Adult Consortium Team: Michal Hammond MD, Valeria Altamirano BS MS, Ali J Smith BS, Carlos Villamizar Rosales MD MS, Nicole Paul BS, Lauren Kaplan BS, Aleksandra S Safonova BS, Charith Ratnayake BS, Adytia D Sharma, Abigail Skeel, Department of Critical Care Medicine, University of Pittsburgh School of Medicine. Neurocritical Care Society, Neurocritical Care Research Central (NCRC), Neurocritical Care Research Network (NCRN).
All authors have contributed to the conception and design of the data fields described in this manuscript, have participated in drafting and critical revisions to the content, and have provided final approval for publication.

\section{Source of support}

This publication was supported by the National Institutes of Health (NIH), National Center for Advancing Translational Sciences (NCATS) through Grant Number(s) UL1 TR001857 (University of Pittsburgh/Chou), the National Institute of Health (R21NS113037, Chou), the University of Pittsburgh Dean's Faculty Advancement Award (Chou).

\section{Conflict of interest}

Dr. Chou reports grants from National Institutes of Health $(\mathrm{NIH})$, National Center for Advancing Translational Sciences (NCATS), grants from National Institute of Health, grants from University of Pittsburgh Dean's Faculty Advancement Award during the conduct of the study. Dr. Fink reports grants from the National Institutes of Health during the conduct of the study. Dr. Mainali reports grant support from Center for Clinical and Translational Science at The Ohio State University sponsored by the National Center for Advancing Translational Sciences-Award Number UL1TR002733 outside the submitted work. Dr. Frontera reports grants from NIH/NIA, grants from NIH/ NINDS during the conduct of the study. The remaining authors declare no conflict of interest related to this work.

\section{Publisher's Note}

Springer Nature remains neutral with regard to jurisdictional claims in published maps and institutional affiliations.

Received: 7 August 2020 Accepted: 1 September 2020 Published online: 18 September 2020

\section{References}

1. Centers for Disease Control. Coronavirus Disease 2019 (COVID-19) Global Response. 2020. https://www.cdc.gov/coronavirus/2019-ncov/globa l-covid-19/global-response.html.

2. Anand P, Lau KHV, Chung DY, et al. Posterior reversible encephalopathy syndrome in patients with coronavirus disease 2019: two cases and a review of the literature. J Stroke Cerebrovasc Dis. 2019;2020:105212.

3. Beyrouti $R$, Adams ME, Benjamin L, et al. Characteristics of ischaemic stroke associated with COVID-19. J Neurol Neurosurg Psychiatry. 2020;91:889-91.

4. Dinkin M, Gao V, Kahan J, et al. COVID-19 presenting with ophthalmoparesis from cranial nerve palsy. Neurology. 2020;95:221-3.

5. Helms J, Kremer S, Merdji $\mathrm{H}$, et al. Neurologic features in severe SARSCoV-2 infection. N Engl J Med. 2020.

6. Herman C, Mayer K, Sarwal A. Scoping review of prevalence of neurologic comorbidities in patients hospitalized for COVID-19. Neurology. 2020;95:77-84.

7. Mao L, Jin H, Wang M, et al. Neurologic manifestations of hospitalized patients with Coronavirus Disease 2019 in Wuhan, China. JAMA Neurol. 2020

8. Merkler AE, Parikh NS, Mir S, et al. Risk of ischemic stroke in patients with coronavirus disease 2019 (COVID-19) vs patients with influenza. JAMA Neurol. 2020

9. Needham EJ, Chou SH, Coles AJ, Menon DK. Neurological implications of COVID-19 infections. Neurocritical Care 2020.

10. Paterson RW, Brown RL, Benjamin L, et al. The emerging spectrum of COVID-19 neurology: clinical, radiological and laboratory findings. Brain J Neurol. 2020.

11. Poyiadji N, Shahin G, Noujaim D, Stone M, Patel S, Griffith B. COVID-19-associated acute hemorrhagic necrotizing encephalopathy: CT and MRI features. Radiology. 2020;201187.

12. Romero Cantero V, Moreno Pulido S, Duque Holguera M, Casado Naranjo I. COVID-19 and concomitant neurological infections. Neurologia (BarceIona, Spain). 2020;35:332-3. 
13. Romero-Sánchez CM, Díaz-Maroto I, Fernández-Díaz E, et al. Neurologic manifestations in hospitalized patients with COVID-19: the ALBACOVID registry. Neurology. 2020.

14. Solomon $I H$, Normandin E, Bhattacharyya S, et al. Neuropathological features of Covid-19. N Engl J Med. 2020. https://doi.org/10.1056/NEJMc 2019373.

15. Toscano G, Palmerini F, Ravaglia S, et al. Guillain-Barre syndrome associated with SARS-CoV-2. N Engl J Med. 2020.

16. Xiong W, Mu J, Guo J, et al. New onset neurologic events in people with COVID-19 infection in three regions in China. Neurology. 2020.

17. Zanin L, Saraceno G, Panciani PP, et al. SARS-CoV-2 can induce brain and spine demyelinating lesions. Acta Neurochir. 2020;162:1491-4.

18. The Lancet Neurology Editors. The neurological impact of COVID-19. Lancet Neurol. 2020;19:471.

19. Saitz R, Schwitzer G. Communicating science in the time of a pandemic. JAMA. 2020.

20. Frontera J, Mainali S, Fink EL, et al. Global consortium study of neurological dysfunction in COVID-19 (GCS-NeuroCOVID): study design and rationale. Neurocritical Care. 2020;1-10.

21. The Neurocritical Care Society. COVID-19 research opportunities. 2020 https://www.neurocriticalcare.org/research/covid-19-research-oppor tunities.

22. The National Institutes of Health. Common data element resource portal. 2020. https://www.nlm.nih.gov/cde/index.html.

23. Suarez Jl, Sheikh MK, Macdonald RL, et al. Common data elements for unruptured intracranial aneurysms and subarachnoid hemorrhage clinical research: a National Institute for Neurological Disorders and Stroke and National Library of Medicine project. Neurocrit Care. 2019;30:4-19.

24. Bellary S, Krishnankutty B, Latha M. Basics of case report form designing in clinical research. Persectives Clin Res. 2014;5:159-66.

25. Godoy DA, Videtta W, Santa Cruz R, et al. General care in the management of severe traumatic brain injury: Latin American consensus. Med. Intensiva. 2020

26. Centers for Disease Control. COVID view: a weekly surveillance summary of U.S. COVID-19 Activity. 2020.

27. Fiser $\mathrm{DH}$. Assessing the outcome of pediatric intensive care. J Pediatr. 1992;121:68-74.

28. Pollack MM, Holubkov R, Glass P, et al. Functional Status Scale: new pediatric outcome measure. Pediatrics. 2009;124:e18-28.

29. Leteurtre S, Duhamel A, Salleron J, Grandbastien B, Lacroix J, Leclerc F. PELOD-2: an update of the PEdiatric logistic organ dysfunction score. Crit Care Med. 2013;41:1761-73.

30. Wolfler A, Osello R, Gualino J, et al. The importance of mortality risk assessment: validation of the pediatric index of mortality 3 score. Pediatr Crit Care Med. 2016;17:251-6.

31. Centers for Disease Control. Multisystem Inflammatory Syndrome in Children (MIS-C) Associated with Coronovirus Disease 2019 (COVID-19). 2020.

32. European Academy of Neurology. EAN neuro-covid registry (ENERGY). 2020. https://www.ean.org/.

33. Winkler AS, Knauss S, Schmutzhard E, Leonardi M, Padovani A, Abd-Allah F, et al. A call for a global COVID-19 neuro research coalition. Lancet Neurol. 2020:19:482-4. 